\title{
Early treatment with inhaled GM-CSF improves oxygenation and anti-viral immunity in COVID-19 induced lung injury - a randomized clinical trial
}

Cedric Bosteels

VIB-Ghent University

Karel Van Damme

VIB-Ghent University https://orcid.org/0000-0002-4379-1047

Elisabeth De Leeuw

VIB-Ghent University

Jozefien Declercq

VIB-Ghent University

\section{Bastiaan Maes}

VIB-Ghent University

Victor Bosteels

VIB-Ghent University

Levi Hoste

Ghent University

Leslie Naesens

Ghent University

Nincy Debeuf

VIB-Ghent University

Julie Deckers

VIB-Ghent University

Daniela Weiskopf

Center for Infectious Disease, La Jolla Institute for Immunology, La Jolla, CA92037, USA

Alessandro Sette

La Jolla Institute for Allergy and Immunology

Yannick Vande Weygaerde

Ghent University

Thomas Malfait

Ghent University

Stefaan Vandecasteele

AZ Sint-Jan Hospital

Ingel Demedts 
AZ Delta General Hospital

\section{Hans Slabbynck}

ZNA General Hospital

\section{Sabine Allard}

Universitair Ziekenhuis Brussel

\section{Pieter Depuydt}

Ghent University

\section{Eva Van Braeckel}

Ghent University https://orcid.org/0000-0002-7242-0747

Jozefien De Clercq

Ghent University

\section{Liesbet Martens}

VIB-Ghent University

\section{Sam Dupont}

VIB-Ghent University

\section{Ruth Seurinck}

VIB-Ghent University

\section{Niels Vandamme}

Cancer Research Institute Ghent (CRIG)

\section{Filomeen Haerynck}

Ghent University Hospital

\section{Debasish Roychowdhury}

Partner therapeutics

\section{Linos Vandekerckhove}

HIV Cure Research Center, Ghent University Hospital https://orcid.org/0000-0002-8600-1631

\section{Martin Guilliams}

VIB-Ghent University

\section{Simon Tavernier}

VIB-Ghent University

Bart Lambrecht ( $\square$ bart.lambrecht@ugent.be)

VIB Center for Inflammation Research

\section{Article}

Keywords: granulocyte-macrophage colony-stimulating factor, alveolar macrophages, rhu-GM-CSF

Posted Date: October 13th, 2021

DOI: https://doi.org/10.21203/rs.3.rs-959220/v1 
License: (c) (i) This work is licensed under a Creative Commons Attribution 4.0 International License. Read Full License 


\section{Early treatment with inhaled GM-CSF improves oxygenation and anti-viral immunity in COVID-19 induced lung injury - a randomized clinical trial}

Cedric Bosteels ${ }^{1,2,3,{ }^{*}}$, Karel F.A. Van Damme ${ }^{1,2,3,{ }^{*}}$, Elisabeth De Leeuw ${ }^{1,2,3,{ }^{*}, \text { Jozefien Declercq }}{ }^{1,2,3,{ }^{*}}$

Bastiaan Maes ${ }^{1,2,3}{ }^{*}$, Victor Bosteels ${ }^{2,3,4}$, Levi Hoste ${ }^{2,5}$, Leslie Naessens ${ }^{2,5}$, Nincy Debeuf ${ }^{1,2,3}$, Julie Deckers $^{1,2,3}$, Daniela Weiskopf ${ }^{6}$, Alessandro Sette ${ }^{6,7}$, Yannick Vande Weygaerde ${ }^{3}$, Thomas Malfait ${ }^{3}$, Stefaan J. Vandecasteele ${ }^{8}$, Ingel K. Demedts ${ }^{9}$, Hans Slabbynck $^{10}$, Sabine Allard ${ }^{11}$, Pieter Depuydt ${ }^{2,12}$, Eva Van Braeckel ${ }^{2,3}$, Jozefien De Clercq ${ }^{2,13}$, Liesbet Martens ${ }^{14,15}$, Sam Dupont ${ }^{1,2,3}$, Ruth Seurinck ${ }^{16,17}$, Niels Vandamme ${ }^{16,18}$, Filomeen Haerynck ${ }^{2,5}$, Debasish F. Roychowdhury ${ }^{19}$, Linos Vandekerckhove ${ }^{2,13}$, Martin Guilliams ${ }^{14,15,{ }^{* *}}$, Simon J. Tavernier ${ }^{2,5,20,21,{ }^{* *}}$, Bart N. Lambrecht ${ }^{1,2,3,{ }^{* *}, \S}$

${ }^{1}$ Laboratory of Mucosal Immunology, VIB-UGent Center for Inflammation Research, Ghent University, Ghent, Belgium

2Department of Internal Medicine and Pediatrics, Faculty of Medicine and Health Sciences, Ghent University, Ghent, Belgium ${ }^{3}$ Department of Respiratory Medicine, Ghent University Hospital, Ghent, Belgium

${ }^{4}$ Laboratory of ER stress and Inflammation, VIB-UGent Center for Inflammation Research, Ghent University, Ghent, Belgium ${ }^{5}$ Primary Immunodeficiency Research Lab, Faculty of Medicine and Health Sciences, Ghent University, Ghent, Belgium ${ }^{6}$ Center for Autoimmunity and Inflammation, and Center for Infectious Diseases and Vaccine Researchation, La Jolla Institute for Immunology, San DiegoLa Jolla, California, USA

${ }^{7}$ Department of Medicine, Division of Infectious Diseases and Global Public Health, University of California, San Diego (UCSD), La Jolla, CA 92037, USA

${ }^{8}$ Department of Infectious Diseases, AZ Sint-Jan Brugge-Oostende, Brugge, Belgium

${ }^{9}$ Department of Pulmonary Medicine, AZ Delta General Hospital, Roeselare, Belgium 
${ }^{10}$ Department of Pulmonary Medicine, ZNA General Hospital, Antwerp, Belgium

${ }^{11}$ Department of Internal Medicine, Universitair Ziekenhuis Brussel, Brussels, Belgium

${ }^{12}$ Intensive Care Unit, Ghent University Hospital, Ghent, Belgium

${ }^{13}$ Department of Infectious Diseases, Ghent University Hospital, Ghent, Belgium

${ }^{14}$ Laboratory of myeloid cell biology in tissue homeostasis and regeneration, VIB-UGent Center for Inflammation Research,

Ghent University, Ghent, Belgium

${ }^{15}$ Department of Biomedical Molecular Biology, Faculty of Sciences, Ghent University, Ghent, Belgium

${ }^{16}$ Data Mining and Modeling for Biomedicine, VIB-UGent Center for Inflammation Research, 9052 Ghent, Belgium.

${ }^{17}$ Department of Applied Mathematics, Computer Science and Statistics, Ghent University, 9000 Ghent, Belgium.

${ }^{18}$ VIB Single Cell Core, VIB-UGent Center for Inflammation Research, Ghent University, Ghent, Belgium

${ }^{19}$ Partner Therapeutics, Inc., Lexington, MA, USA

${ }^{20}$ Department of Biomedical Molecular Biology, Faculty of Sciences, Ghent University, Ghent, Belgium

${ }^{21}$ Laboratory of Molecular Signal Transduction in Inflammation, VIB Ugent Center for Inflammation Research, Ghent, Belgium.

*Authors contributed equally

**Shared last authors

${ }^{\S}$ Corresponding author 


\section{ABSTRACT}

Granulocyte-macrophage colony-stimulating factor (GM-CSF) instructs monocytes to differentiate into alveolar macrophages (AM) that preserve lung homeostasis. By comparing AM development in mouse and human, we discovered that COVID-19 patients showed marked defects in GM-CSF-dependent AM instruction. The multi-center, open-label, randomized, controlled SARPAC-trial evaluated the efficacy and safety of 5 days of inhalation of rhu-GM-CSF (sargramostim, Leukine ${ }^{\circledR}$ ) in 81 non-ventilated patients with COVID-19 and hypoxemic respiratory failure identified by $\mathrm{PaO}_{2} / \mathrm{FiO}_{2}$ ratio $<350 \mathrm{mmHg}$. At day 6 , more patients in the sargramostim group experienced at least $25 \%$ improvement in oxygenation compared with the standard of care group. Higher numbers of circulating class-switched B cells and effector virus-specific CD8 lymphocytes were found in the sargramostim group. Treatment adverse events, including signs of cytokine storm, were not different between active and control group. This proof-of-concept study demonstrates the feasibility and safety of inhaled GM-CSF in restoring alveolar gas exchange, while simultaneously boosting antiCOVID-19 immunity. ClinicalTrials.gov (NCT04326920). 


\section{BACKGROUND}

Gas exchange in the lungs occurs in the alveoli, over a thin alveolocapillary membrane that allows the rapid diffusion of oxygen and carbon dioxide between the alveoli and the red blood cells that circulate in the lung capillaries. When pathogens or dust particles enter the lung, inflammation and edema in the alveolar wall is therefore always kept to a minimum, to protect the delicate gas exchange apparatus. The alveolocapillary membrane is however also an easy portal of pathogen entry into the bloodstream and needs to be defended. One way by which evolution has solved the problem of lung defense in the absence of inflammation is via the unique placement of alveolar macrophages (AM) as first line of defense. Tissue resident AM adhere to and crawl on alveolar epithelial cells and in this exposed position continuously capture, phagocytose, conceal and neutralize a large cargo of pathogens and particles from inhaled air, without causing inflammation ${ }^{1-3}$. At the same time, AMs handle and recycle surfactant, a detergent that keeps alveoli in an open inflated state by lowering the surface tension of the alveolar lining fluid ${ }^{4}$. Tissue resident AM develop early in life, and can occupy the alveolar niche through local low-grade proliferation without the need for replenishment by circulating monocytes ${ }^{5}$. Within the first week of life, alveolar epithelial-cell derived granulocyte-macrophage colony stimulating factor (GM-CSF) provides the instructive signal that programs fetal monocytes to become homeostatic tissue-resident AMs in the alveolar niche ${ }^{5-9}$. These resident $A M s$ then self-maintain with only minimal input from circulating monocytes in both mouse $\mathrm{s}^{5,10,11}$ and human ${ }^{12-14}$. Severe inflammatory insults can however temporarily deplete tissue resident AM and lead to the recruitment of monocytes that can later develop into long-lived AMs when tissue homeostasis is restored ${ }^{10,15,16}$. 
In patients with severe Coronavirus disease 2019 (COVID-19), infection with SARS-CoV-2 virus has profound effects on alveolar homeostasis, , resulting in hypoxemia through impaired alveolo-capillary gas exchange and disbalances in the ratio of lung ventilation and perfusion, potentially culminating in the acute respiratory distress syndrome (ARDS) $)^{17,18}$. The initial viral replication phase that occurs in lung alveolar epithelial cells (AECs), AMs and capillary endothelial cells is followed by a second hyperinflammatory phase in which alveolar homeostasis is severely disturbed. During this phase of hyperinflammation, there is activation of the complement and coagulation cascade leading to inflammatory cell recruitment, and to microthrombi in the alveolar capillaries ${ }^{19,20}$. Simultaneously, there is release of cytokines that act systemically to induce profound fever, overproduction of ferritin and acute phase proteins by the liver, progressive dysfunction of the liver, kidney and heart, and depletion of circulating lymphocytes and eosinophils through hemophagocytosis or suppression of hematopoiesis ${ }^{18,}$ 20-26. Currently, oxygen supplementation and ventilatory support, anti-coagulation, systemic steroids, and cytokine blockade are the mainstay of therapy for severe COVID-19, but therapies aimed at restoring alveolar homeostasis are lacking.

Most reports that have studied inflammation in the lung alveoli in severe COVID-19 have found an accumulation of dysregulated myeloid cells including neutrophils and macrophages in the bronchoalveolar space, and these can lead to a state of immune silence hampering $\mathrm{T}$ cell activation ${ }^{27-34}$. Although macrophages and monocytes recovered by bronchoalveolar lavage are often termed AM, careful single cell mRNA analysis of BAL fluid cells has shown that the accumulation of heterogeneous pro-inflammatory and immunosuppressive monocytederived macrophages is at the same time accompanied by the loss of homeostatic tissue 
resident $A M s$, that can be reliably identified using a set of gene transcripts that include FABP4 and PPARG $27,30,35$. The precise reason for the loss of tissue resident AM is currently unknown, but of great interest, since restoring AM function might herald return of alveolar homeostasis, relief from immune suppression and could form the basis of innovative therapy.

In an attempt to find new therapeutic options for severe COVID-19, we first studied the composition of BAL fluid immune cells in patients with confirmed COVID-19 pneumonia or patients with non-COVID lung infection or undergoing diagnostic bronchoscopy for other reasons. By comparing scRNAseq and CITEseq data from COVID-19 lung samples with transcriptomic data of murine fetal monocytes developing into AMs in wild type and $C s f 2^{-/}$ mice, we found that human COVID-19 lung macrophages are characterized by the loss of an evolutionary conserved GM-CSF-mediated instruction that drives AM development. Based on this translational finding, we initiated the SARPAC (SARgramostim in Patients with Acute COVID-19) randomized controlled proof-of-concept clinical trial that investigated the feasibility and safety of inhaled sargramostim (rhu-GM-CSF, Leukine ${ }^{\circledR}$ ) treatment for hospitalized COVID-19 patients with signs of hypoxemia requiring oxygen supplementation ${ }^{36}$. The primary objective was to study the impact and safety of 5 days of sargramostim inhalation treatment on parameters of alveolar gas exchange, while exploratory analysis included effects of sargramostim on development of cytokine storm and antiviral immunity. 


\section{RESULTS}

\section{Lack of alveolar macrophages and GM-CSF instruction in COVID-19 patients}

We profiled mRNA levels of 223.927 individual BALF cells from 19 hospitalized patients (Extended Data Table 1 for clinical characteristics) with COVID-19 (n=8), non-COVID-19 pulmonary infection ( $n=8)$, interstitial lung disease (ILD) $(n=1)$ and control non-infected individuals undergoing diagnostic bronchoscopy $(n=2)$. The analysis of the BALF cells not only included single-cell 3' RNA-sequencing, but also quantitative measurement of surface proteins using panels of more than 277 oligo-conjugated antibodies (TotalSeq A - CITEseq), of which the 120 best expressing clones were retained for this analysis (Fig. 1a), thus combining proteomic and transcriptomic information at single cell resolution ${ }^{37,}{ }^{38}$. The complete proteogenomic information was utilized for the single cell analysis by applying TotalVI ${ }^{39}$, an algorithm that combines protein and mRNA profiles for the cell clustering in the dimensionality reduction by uniform manifold approximation and projection (UMAP).

This analysis revealed 12 distinct cell subsets (Fig. 1a; Extended Data Fig. 2a), which were each annotated based on differentially expressed genes and surface proteins (DEGs; DEPs). We identified monocytes $\left(F C N 1^{+} V C A N^{+} ; \quad C D 14^{+} C D 244^{+}\right)$, macrophages $\left(F A B P 4^{+} C 1 Q A^{+}\right.$;

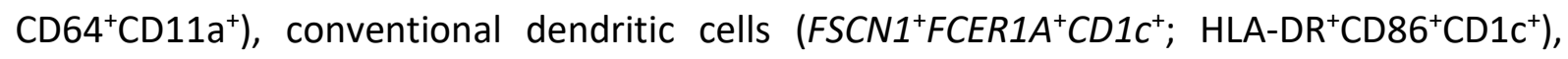
plasmacytoid dendritic cells (SPIB LILRA4 $^{+}$; CD162 $\left.{ }^{+} \mathrm{CD} 62 \mathrm{~L}^{+} \mathrm{CD} 304^{+}\right)$, B cells $\left(C D 79 A^{+} M S 4 A 1^{+}\right.$;

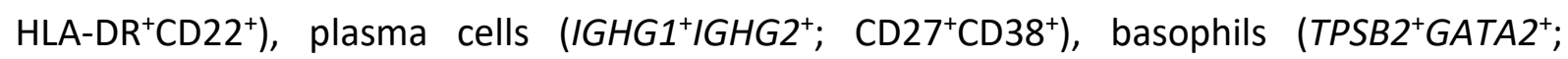
$\left.\mathrm{CD} 22^{+} \mathrm{CD} 151^{+}\right)$, T cells $\left(C D 3 D^{+} C D 2^{+} ; \mathrm{CD}^{+} \mathrm{CD}^{+}\right)$, NK cells $\left(\mathrm{KLRC1}^{+} X C L 1^{+} ; \mathrm{CD}^{+} \mathrm{CD} 49 \mathrm{a}^{+}\right)$, 
neutrophils (CXCR1 $\left.{ }^{+} F C G R 3 B^{+} ; C^{2} 16^{+} C D 35^{+}\right)$, ciliated cells $\left(T T C 29^{+} H Y D I N^{+} P R O M 1^{+} ; C D 133^{+}\right)$and epithelial cells (SFTPD ${ }^{+}$SFTA2 ${ }^{+}$; CD142 ${ }^{+}$CD26 ${ }^{+}$) (Fig. 1a; Extended Data Fig. 1 and Fig. 2a). Lymphocytes, monocytes and neutrophils were enriched in COVID-19 patients, while macrophages were depleted (Extended Data Fig. 2b). We performed a more in-depth analysis of the monocyte and macrophage clusters ( 55.304 cells in total) which could be further

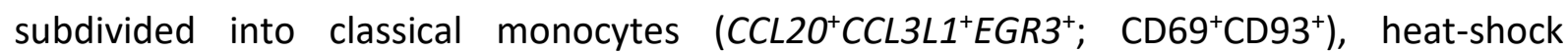
monocytes (HSPA1 $\left.1^{+} D N A J B 1^{+} H S P A 6^{+}\right)$, IFN-stimulated monocytes $\left(I F I T 1^{+} C X C L 10^{+} R S A D 2^{+}\right)$,

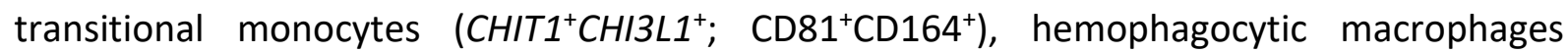
$\left(S L C 4 O A 1^{+}\right.$FOLR2 ${ }^{+} ;$FOLR2 $\left.{ }^{+} M E R T K^{+} C D 163^{+}\right)$and tissue resident AMs $\left(L G A L S 3^{+}\right.$FABP4 $4^{+} M^{+} E^{+}$; $\mathrm{CD} 10^{+} \mathrm{CD}_{204^{+}} \mathrm{Mac2}^{+}$) (Fig. 1b-d; Extended Data Fig. 2d, e, g and h).

The different clusters, and monocytes/macrophages in particular, showed specific enrichment in different patient groups (Fig. 1e; Extended Data Fig. 2c, 2f). In patients with COVID-19 and non-COVID-19 pulmonary infection, tissue resident AM proportions were strongly reduced, while IFN-stimulated monocytes and $\mathrm{CD} 163^{+}$hemophagocytic macrophages were enriched compared to healthy controls and a patient with ILD (Fig. 1e; Extended Data Fig. 2c). Hemophagocytic macrophages and transitioning monocytes were more enriched in COVID-19 pneumonia compared with a non-COVID-19 pneumonia. To model the differentiation process of monocytes and macrophages in an unbiased way, we performed a trajectory inference analysis using Slingshot ${ }^{40}$ (Fig. 1d-e). This algorithm predicted a trajectory starting from the monocyte cluster differentiating into IFN-stimulated monocytes or transitional monocytes. The transitional monocyte cluster then further bifurcates into hemophagocytic macrophages 
or tissue resident AMs (Fig. 1f). In healthy controls, the end state of most monocytes/macrophages was the tissue resident AM fate (Fig. 1g left panel), whereas in COVID-19 patients most monocytes were predicted to differentiate into IFN-stimulated monocytes and hemophagocytic macrophages and not tissue resident AMs (Fig. 1g right panel). The presence of $\mathrm{CD}_{163^{+}}$hemophagocytic macrophages in the alveolar lumen was also confirmed by immunohistochemistry in a fatal case of COVID-19 (Fig. 1d). So, in line with earlier reports ${ }^{27,30,35}$, we found that lung monocytes in COVID-19 patients fail to develop into AMs yet turn into highly pro-inflammatory monocytes and $\mathrm{CD}_{163^{+}}$hemophagocytic macrophages in the alveolar lumen.

We next aimed to unravel the mechanisms hampering monocyte to AM instruction during COVID-19. To more closely understand AM development, we turned to the mouse model, where the various stages of AM development from fetal monocytes and AM instruction by epithelial cell derived GM-CSF (encoded by the Csf2 gene) have been closely described by us and others ${ }^{5-7,41}$. We sorted lung monocyte and developing AM populations from lung tissue of wild-type mice at different time points from embryonic day 15 until adulthood and performed transcriptional micro-array analysis on these developmental stages (Fig. 1h). First, we focused on the genes that shared three characteristics: they were (i) AM specific and not found in other tissue resident macrophages ${ }^{42}$, (ii) lost in $C s f 2^{--}$mice and (iii) rescued in $C s f 2^{-/-}$ mice upon treatment with inhaled GM-CSF. We regarded these genes reflective of the "murine GM-CSF-dependent lung macrophage signature" (Fig. 1i). Accordingly, neonatal and postnatal day 9 (PND9) lung macrophages already strongly resembled adult tissue resident AMs at 
a transcriptional level and acquired key adult tissue resident AM genes such as Ear1, Plet4 and Pparg (Fig. 1i). Macrophages sorted from the alveolar lumen of PND9 Csf2 $\%$ mice lacked this GM-CSF-dependent AM signature, but early life inhaled treatment with recombinant GM-CSF (rGM-CSF) in $\mathrm{Csf2}^{-}$mice restored this gene signature (Fig. 1i right column). Next, we looked into genes that were (i) upregulated in macrophages in $C s f 2^{--}$mice as compared to wild type AMs, but (ii) were downregulated again upon treatment with inhaled GM-CSF (Fig $1 \mathrm{j}$ right column). These genes thus reflect the lack of GM-CSF instruction and therefore considered as the "murine lack-of-GM-CSF lung macrophage signature" (Fig. 1j). Some of these genes are clearly pro-inflammatory and driven by type I interferon signaling, such as $\mathrm{Cxc} / 9, \mathrm{Cxc} / 10$, Ifit1, Ifit2 and Rsad2 (Fig 1j). Altogether, this demonstrates that (i) GM-CSF is not only a critical instructive cytokine for murine tissue resident $A M$ differentiation ${ }^{5}$ but also that (ii) lung monocytes develop into pro-inflammatory cells in the absence of GM-CSF, a state that is however reversible by inhaled GM-CSF treatment.

Finally, we compared murine AM differentiation transcriptional states with human COVID-19 scRNAseq datasets. We projected the murine GM-CSF-dependent lung macrophage signature on the patients BALF clusters obtained from sequencing data. Genes associated with presence of GM-CSF (Fig. 1i), as for example $P P A R G^{7}$ (Fig. 1l left UMAP), were highly expressed by human tissue resident AMs found in healthy controls (Fig. 1k left UMAP). Vice versa, genes upregulated in the absence of GM-CSF (Fig. 1j), as CXCL10 (Fig. 1l right UMAP), IL18BP, TNFSF13B and MMP14, were enriched in IFN-stimulated monocytes and hemophagocytic macrophages from COVID-19 infected patients (Fig. 1k right UMAP). In conclusion, these data 
demonstrated that mononuclear cells in the lungs of COVID-19 patients lacked evolutionary conserved GM-CSF instruction, leading to a lack of tissue resident AM and accumulation of pro-inflammatory monocyte/macrophage populations typically seen in GM-CSF deficient states. This provided the rationale for a randomized clinical trial where inhaled GM-CSF was administered to hypoxemic COVID-19 patients, in an attempt to improve alveolar homeostasis, with the underlying hypothesis that such treatment would promote the differentiation of transitional monocytes into AMs, reduce hyperinflammation, and restore the gas exchange apparatus.

\section{Patients enrolled in SARPAC randomized clinical trial of inhaled GM-CSF}

From March 25 through September 28, 2020, 81 hospitalized COVID-19 patients were included in the SARPAC trial at 5 participating sites in Belgium. Enrolled patients had acute hypoxemic respiratory failure (oxygen saturation below $93 \%$ on $\geq 2$ liters oxygen per minute or a ratio of the partial pressure of oxygen $(\mathrm{PaO} 2)$ to the fraction of inspired oxygen $(\mathrm{FiO} 2 ; \mathrm{P} / \mathrm{F}$ ratio) below $350 \mathrm{mmHg}$ ). Patients with a serum ferritin $>2000 \mu \mathrm{g} / \mathrm{L}$ or already on mechanical ventilation were excluded from participation. All participants provided oral and written consent (full clinical study protocol available in Extended Data). Eighty-one patients were randomly assigned in a 1:1 ratio to receive 5 days of twice daily $125 \mu \mathrm{g}$ of inhaled sargramostim (rhu-GM-CSF, Leukine ${ }^{\circledR}$ ) on top of standard of care (SOC) or to SOC alone (Fig. 2). Two patients in the sargramostim group showed progression of disease within the first 5 days requiring initiation of mechanical ventilatory support. In these patients inhaled sargramostim was replaced per protocol by intravenous sargramostim $125 \mu \mathrm{g} / \mathrm{m}^{2}$ body 
surface area, to minimize risk of aerosol spread in the ICU. Four additional patients in the sargramostim group and two patients in the SOC group received i.v. sargramostim from day 6 onwards (after the primary endpoint was measured), based on clinician's decision when deterioration occurred.

Seventy-three patients reached the evaluable primary endpoint (oxygenation parameters at day 6). Two patients discontinued treatment prematurely, three patients refused arterial puncture at day 6, and another three patients were excluded from analysis because they had a negative $\mathrm{P}(\mathrm{A}-\mathrm{a}) \mathrm{O}_{2}$ gradient at randomization or day 6 , signifying an error in $\mathrm{FiO}_{2}$ recording. All primary efficacy evaluable patients $(\mathrm{N}=73)$ were included in a modified intention-to-treat analysis. All patients $(\mathrm{N}=81)$ were included in the safety population. A follow-up evaluation 10-20 weeks after randomization was completed in 28 of 40 patients (70.0\%) in the sargramostim group and in 33 of the 41 patients $(80.5 \%)$ in the control group. No patients discontinued participation because of safety reasons.

The patients baseline demographic, clinical and biological characteristics and co-administered medications were broadly similar across both groups (Table 1). The median age was 60 years (interquartile range (IQR), 46-69 years) and the majority (63.0\%) were male. The degree of hypoxia (either as $-\mathrm{P}(\mathrm{A}-\mathrm{a}) \mathrm{O}_{2}$ gradient or as $\mathrm{PaO}_{2} / \mathrm{FiO}_{2}$ ratio) was comparable across groups. Only a minority of included patients received glucocorticoids, anti-viral drugs or antibiotics, whereas a majority received hydroxychloroquine at time of randomization. The median ferritin at baseline was $721 \mu \mathrm{g} / \mathrm{L}$. Biomarkers measured in serum, such as IL-6 and GM-CSF, were similar across both groups at randomization. The majority of patients $(87.7 \%)$ required 
supplemental oxygen and only a minority were on high flow oxygen devices (7.4\%) at time of inclusion.

\section{Effect of sargramostim inhalation on primary endpoint}

The proportion of patients with at least $25 \%$ improvement in lung oxygenation parameters after 5 days of treatment compared to baseline values was higher in the sargramostim group than in the SOC group (Table 2 and Extended Data Fig. 3a-b) when assessed by measuring the gradient between partial pressure of oxygen between the alveolar air and the arterial blood $\left(\mathrm{P}(\mathrm{A}-\mathrm{a}) \mathrm{O}_{2}\right.$ gradient; $22 / 35(62.9 \%)$ vs. $\left.15 / 38(39.5 \%) ; \mathrm{P}=0.0459\right) . \mathrm{P}(\mathrm{A}-\mathrm{a}) \mathrm{O}_{2}$ gradient is a marker for alveolar gas exchange and ventilation/perfusion mismatch. This was also the case when improvement was defined by a more marked improvement of at least $33 \%$ in $\mathrm{P}(\mathrm{A}-\mathrm{a}) \mathrm{O}_{2}$ gradient (19/35 (54.3\%) vs. $10 / 38(26.3 \%) ; P=0.0147)$ or of at least $50 \%$ improvement $(12 / 35$ $(34.4 \%)$ vs $6 / 38(15.8 \%) ; P=0.1023)$. The proportion of patients showing at least $25 \%$ improvement in the $\mathrm{PaO}_{2} / \mathrm{FiO}_{2}$ ratio, another measure of oxygenation often used in the ICU setting in ventilated patients, was not statistically different between groups (11/35 (31.4\%) vs. $11 / 38(28.9 \%) ; \mathrm{P}=0.817)$. However, the absolute median improvement in the $\mathrm{PaO}_{2} / \mathrm{FiO}_{2}$ ratio was higher in the sargramostim compared with the control group (median change from baseline, $+58.0(-3,+64) \mathrm{mmHg}$ in vs. $+20.0(-10,+61) \mathrm{mmHg} ; \mathrm{P}=0.0818)$, with borderline statistical significance (Table 2).

Certain subsets of patients defined by concomitant therapy, clinical severity or biomarkers may have responded differently, akin to the response in other cytokine intervention 
strategies ${ }^{43}$. However, no evidence for an enhanced treatment effect of sargramostim could be found in post-hoc specified subgroups (concomitant glucocorticoid use, $P(A-a) O_{2}$ gradient above or below the median value at randomization, CRP and ferritin level at randomization above or below the median value), although patients numbers were small to draw definitive conclusions (Extended data Fig. 4).

\section{Effect of sargramostim inhalation on secondary clinical and safety end points}

In this small proof-of-concept study, no evidence for a treatment effect of sargramostim could be found for any of the supportive endpoints listed in Table 2, including duration of hospital stay, progression to mechanical ventilation or ARDS, and all-cause mortality rate at 4 weeks post-randomization. Initially, we had planned to look at incidence of secondary hemophagocytic lymphohistiocytosis (HLH), but incidence was so low that scoring for this parameter was discontinued. Patients were also seen at follow up 10-20 weeks following hospital discharge, to study development of secondary lung fibrosis by high resolution computed tomography (HRCT) fibrosis score analysis. However, the incidence of fibrotic changes was so low in both groups we could not make an assessment of this secondary endpoint.

Adverse events were generally balanced between both groups, except for mild epistaxis which was more reported in the sargramostim group (20.0\% versus $4.9 \%$ in SOC). For the serious adverse events (SAEs) not leading to mortality, we did not observe differences between both groups (Table 3). Overall, twelve patients died during the study, of which one patient during 
the first 6 days and 4 patients during the first 28 days after randomization. We did not find evidence for differences in mortality between study arms and if any, mortality was higher in the control group (Table 3).

\section{Effect of sargramostim inhalation on innate immune landscape}

Inappropriate and uncontrolled release of pro-inflammatory cytokines such as TNF $\alpha$, IL-1, IL6, IL-8 and IL-18 contributes to disease progression and is associated with worse prognosis in patients with severe COVID-1925, 43, 44. Since increased numbers of GM-CSF producing T cells ${ }^{31}$ and higher serum concentrations ${ }^{45}$ of GM-CSF were reported in some patients with COVID-19, and since GM-CSF can boost the production of pro-inflammatory cytokines and is even blocked in several ongoing COVID-19 trials ${ }^{46}$, an a priori defined pharmacodynamic endpoint was to study signs of enhancement of cytokine release syndrome by inhaled sargramostim. For patients in 3 selected study sites, we quantified serum concentrations of pro-inflammatory cytokines at randomization and day 6 , and compared these with a cohort of age-matched healthy controls (HC). Although pro-inflammatory cytokines were higher in COVID-19 patients at randomization, they declined over the next days and were not increased by 5 days of sargramostim (Fig. 3a). At randomization, serum concentration of GM-CSF was low in most patients and comparable to HC samples (Extended data Fig. 5a). Cytokine release promotes complement activation and thrombosis, which are ominous drivers of severe COVID-19 immunopathology 20,47 . The anaphylatoxin $\mathrm{C} 5 \mathrm{a}$ promotes alveolar inflammation by recruitment of $\mathrm{C} \mathrm{aR}^{+}$neutrophils and monocyte-derived cells ${ }^{48}$, and $\mathrm{C} 5 \mathrm{a}$ concentration was higher in COVID-19 patients in our cohort, compared with $\mathrm{HC}$ at randomization. At day 6, C5a 
concentration dropped independently of sargramostim treatment (Fig. 3b). High serum concentrations of ferritin and CRP, and low circulating numbers of lymphocytes and eosinophils can also be a sign of cytokine release syndrome or secondary HLH in COVID-19, and these were measured as part of the secondary and safety assessment. Between randomization and day 6 , virtually all patients demonstrated amelioration of these key laboratory parameters, irrespective of their treatment arm (Table 2). Systemic GM-CSF has been shown to promote the priming of neutrophils in other forms of ARDS, and low density $\mathrm{CD}_{24}{ }^{+}$activated neutrophils ${ }^{49}$ were seen in higher numbers in our COVID-19 cohort, compared with HC. Sargramostim treatment did however not promote this neutrophil activation state (Fig 3b). GM-CSF is the prototypical growth factor for DCs, and circulating cDC2s, CDC3s and pDCs were depleted in COVID-19 patients at randomization and after 6 days, irrespective of sargramostim treatment, and similar findings were seen for circulating basophils (Extended data Fig. 5b). Systemic GM-CSF promotes emergency hematopoiesis, and could be involved in expansion of myelomonocytic cells ${ }^{21}$. However, after 6 days of follow up, there was no increase in the percentage of $\mathrm{CD} 14^{+}$or $\mathrm{CD} 16^{+}$monocytes, in patients receiving sargramostim, compared with those in the SOC group (Fig. 3b). Downregulation of HLA-DR on monocytes is frequently found in ARDS associated immunosuppression ${ }^{50}$, and we did find evidence of this in our COVID-19 patients at randomization, compared with HC (Fig 3c). Six days later however, HLA-DR expression on monocytes was restored, irrespective of the treatment arm.

\section{Effect of sargramostim inhalation on adaptive antiviral immune response}


Both humoral and cellular (cytotoxic) immune responses are important for elimination of viral particles, and the accumulation of monocyte-derived macrophages seen in COVID-19 patients has been proposed to contribute to an immune silenced state in which it is hard to activate adaptive immune cells ${ }^{29}$. GM-CSF has demonstrated significant immune stimulating effects in models of bacterial and viral lung infection ${ }^{51-53}$. To investigate whether inhaled GM-CSF altered the cellular and humoral immune response against SARS-CoV-2, we set up a predefined analysis of $\mathrm{B}$ and $\mathrm{T}$ cell responses and immunoglobulins by high-dimensional flow cytometry on PBMCs and serum ELISA. Circulating switched memory B cells were significantly increased after 5 days of treatment with sargramostim (Fig. 3d), whereas plasmablasts were unaltered (Extended data Fig. 5c). Virus-specific humoral responses assessed by quantifying both IgG and IgA directed against the receptor binding domain (RBD) of the spike (S1) protein and IgG directed against the nucleocapsid protein (NCP), were markedly increased in both the SOC and sargramostim group (Fig. 3e) after 5 days of treatment. In parallel, we studied cellular immune responses. We observed a significant increase of activated $\mathrm{CD} 38^{+} \mathrm{HLA}^{-\mathrm{DR}^{+}}$effector memory (EM) CD8 T cells after 5 days of sargramostim treatment but not in the control group (Fig. 3f). We finally addressed if these $T$ cell responses were specifically directed against the virus, and therefore stimulated T cells with a megapool (MP) of 221 peptides (15-mer) spanning the entire S protein SARS-CoV-2, or with 246 predicted MHCII-restricted or 628 predicted $\mathrm{MHCl}$-restricted peptides covering the rest of the SARS-CoV-2 proteome ${ }^{54,55}$. After stimulation with the CD8 MP, the number of IFN $\gamma$ producing cells in an ELISpot assay were significantly increased after 5 days of sargramostim treatment compared to SOC, and some of these cells simultaneously produced IL-2 (Fig. 3g. A major expansion of activated CD38 ${ }^{+} \mathrm{HLA}-$ $\mathrm{DR}^{+} \mathrm{EM}$ CD4 T cells was not observed upon sargramostim inhalation (Extended data Fig. 5d,e). 
Together, these data demonstrate that inhalation of sargramostim in COVID-19 patients is feasible and safe, leading to improved gas exchange in the lung, while simultaneously boosting the immune response against the virus. 


\section{DISCUSSION}

Several papers have shown that COVID-19 is accompanied by influx of mononuclear cells in the alveolar space, at the expense of tissue resident AM which normally stably occupy this niche ${ }^{27-30,32}$. The precise reasons for deficiency in tissue resident AMs in COVID-19 have remained elusive, and one possible explanation was that AMs are directly infected by SARS$\mathrm{CoV} 2^{35}$. This leaves the question why recruited newcomer monocytes fail to differentiate into tissue resident AMs when they encounter an empty alveolar niche. By comparing scRNAseq and CITEseq data from COVID-19 lung samples with mini-bulk transcriptomic data of the various stages of fetal and postnatal AM development in wild type mice and GM-CSF-deficient mice, we found that recruited lung macrophages in COVID-19 lungs lack GM-CSF instruction. GM-CSF is the prime cytokine of the alveolar niche, produced by type II alveolar epithelial cells $(\mathrm{AEC})^{6}$. This cytokine induces the master lipid-handling transcription factor PPAR $\gamma$, and causes fetal and adult monocytes to differentiate into tissue resident $\mathrm{AMs}^{5,7,41}$. In adult mice, the return of tissue resident AMs following their depletion by infectious insults depends on GMCSF production by type II AECs ${ }^{6,56}$. We have tried to measure GM-CSF levels in the BAL fluid of COVID-19 patients and other pulmonary infections but failed to detect it (data not shown), and serum levels of GM-CSF were very low in our cohort, despite an earlier report ${ }^{45}$. Several explanations are possible for the lack of GM-CSF instruction on recruited monocytes in COVID19 lungs. First, through their expression of ACE2 receptor, type II AECs are prime targets of SARS-CoV2 infection ${ }^{28,35}$, so demise of these cells in COVID-19 pneumonia would lead to loss of a major source of GM-CSF. Such a scenario has indeed been described in other forms of ARDS and acute lung injury, where maintained GM-CSF and thus reduced AECII injury or better AECII regeneration was associated with better survival ${ }^{57,58}$. Secondly, subversion of GM-CSF 
production might be unique to the beta-coronavirus family. The SARS-CoV1 virus 3C-like proteinase, which is conserved in SARS-CoV2, specifically subverts the production of GM-CSF but not other cytokines when overexpressed in lung epithelial cells ${ }^{59}$. Finally, the inflammatory milieu of the COVID-19 lung with high numbers of neutrophils and pro-inflammatory cytokines could inhibit the differentiation of AMs by competing for available GM-CSF ${ }^{60}$ or by antagonizing downstream signaling induced by GM-CSF instruction. Indeed, hyperinflammation in COVID-19 is accompanied by oxidative stress, a known suppressor of GM-CSF production by type II AECs ${ }^{61}$.

Previous work in patients with pulmonary alveolar proteinosis (PAP), a disease caused by autoantibodies to GM-CSF or by genetic defects in CSF2RA have also shown that human AMs fail to differentiate into the anti-inflammatory surfactant-handling cells that AMs normally are. Not surprisingly, inhalation of GM-CSF has been proposed as a treatment for this rare disorder, with no noticeable side effects yet durable and favorable outcome on lung function ${ }^{9,62-64}$. Based on our translational findings in mice and humans, and the prior success of inhaled GMCSF therapies in humans, we initiated a randomized controlled proof-of-concept clinical trial to study if inhaled sargramostim treatment would improve alveolar oxygenation, a primary readout of the function of the alveolus. After 5 days of inhaled sargramostim, we found more patients with at least $25 \%$ improved oxygenation, as measured by a decrease in the $\mathrm{P}(\mathrm{A}-\mathrm{a}) \mathrm{O}_{2}$ gradient, a measure for the degree of ventilation/perfusion mismatch and shunting often seen in patients with ARDS. When measured using the $\mathrm{PaO}_{2} / \mathrm{FiO}_{2}$ index, part of the standard assessment of ARDS, the outcome was less clear however. Recently, it was proposed that the 
$\mathrm{PaO}_{2} / \mathrm{FiO}_{2}$ index should be abandoned in COVID-19 trials ${ }^{65}$, since it is inherently variable and heavily influenced by the $\mathrm{FiO}_{2}$ denominator, which is always an estimate in patients breathing spontaneously ${ }^{66}$. We did not perform pre-intervention and post-intervention bronchoscopy in this clinical trial setting in infectious COVID-19 patients, to minimize risk for staff and discomfort for critically-ill patients. We can therefore only speculate why alveolar oxygenation improved in sargramostim-treated patients. Based on our translational studies in mice that were treated with inhaled GM-CSF, one obvious explanation is that alveolar inflammation was suppressed via differentiation of locally recruited monocytes, and their instruction and differentiation into homeostatic tissue resident AM. In fact, a previous study of inhaled sargramostim in the setting of pneumonia-associated ARDS in ventilated patients has shown that defective differentiation of AM was restored, concomitant with improved lung mechanics (compliance) and gas exchange ${ }^{67}$. Similarly, two trials studying intravenous GM-CSF in sepsisassociated ARDS patients found improvements in alveolar gas exchange, however without improving survival ${ }^{68,69}$. In animal models, GM-CSF inhalation and autocrine GM-CSF release in the lung has been shown to improve alveolocapillary barrier function, minimize alveolar water loss and edema, and to directly promote epithelial repair, that are critical to maintain or restore alveolar gas exchange $\mathrm{5}^{57,70}$. Finally, we could also show that GM-CSF inhalation directly boosted B cell responses and SARS-CoV-2 specific CD8 T cell responses. This is in line with previous mouse models of viral or bacterial pneumonia, in which endogenous release of GMCSF, or alternatively its lung-directed overexpression or administration, led to better antiviral immune responses and better overall survival ${ }^{51,52,71,72}$. Like others, we detected a deficiency in at least circulating DC subsets in our cohort of COVID-19 patients, and remaining DCs were 
reported as hypofunctional ${ }^{73}$. GM-CSF is the prime cytokine boosting the numbers and the function of DCs that cross-present antigens derived from infected AECs to CD8 T cells ${ }^{52,53}$.

Despite the beneficial effects of lung GM-CSF on alveolar homeostasis, gas exchange and antimicrobial immunity, not only described in the literature, but also emanating from our clinical intervention, there is still a lot of controversy surrounding GM-CSF as a therapeutic target in this disease ${ }^{46,74}$. Indeed, given the known role of GM-CSF in emergency myelopoiesis and CAR-T cell associated cytokine release syndrome ${ }^{75}$, and the observation of increased numbers of GM-CSF producing T cells ${ }^{31}$ and higher serum concentrations ${ }^{45}$ of GM-CSF in some patients with COVID-19, blockade of systemic GM-CSF or its receptor was also proposed as a strategy to dampen hyperinflammation in severe COVID-19. At least six randomized clinical trials have been launched since the beginning of the pandemic ${ }^{46}$, one of which already reported promising results on a preprint server ${ }^{76}$, while another did not show benefit and was prematurely halted ${ }^{77}$. Major differences in outcome of GM-CSF interventions might depend on timing of intervention, but also on the route of administration. Although our study's primary endpoint was oxygenation after 5 days of inhaled GM-CSF, the protocol did allow for systemic administration based on clinician's decision after the 6-day period in both study arms, if clinical deterioration occurred. Although only 8 patients received i.v. GM-CSF after the primary endpoint analysis, this form of treatment was also not associated with more adverse events, in line with earlier observations in sepsis and pneumonia-associated ARDS patients ${ }^{68,}$ 69. Clearly, more needs to be learned about the precise timing of sargramostim treatment, and three large randomized controlled trials have been initiated (NCT04642950, NCT04411680; 
NCT04707664), the latter of which is in the ambulatory setting in patients with much milder symptoms.

Three main limitations of SARPAC need to be acknowledged and include the open-label design, reliance on the surrogate primary endpoint of 'oxygenation' and exclusion of patients with critical COVID-19. An open-label design was used given logistical and safety challenges. For safety reasons sargramostim nebulization was always performed in negative pressure rooms, however nebulization of placebo was not performed in order to avoid unnecessary generation of aerosols. Allocation of a patient to the sargramostim group might have influenced hospital stay and timing of ABG analysis due to the patient's or treating physician's desire to complete the treatment regime. $\mathrm{PF}$ ratio or $\mathrm{P}(\mathrm{A}-\mathrm{a}) \mathrm{O}_{2}$ gradient are objective measures of gas exchange and serve as meaningful surrogates for severity of lung injury. However, the study is underpowered to capture impact of improved oxygenation on clinical outcomes and mortality. The low $28-d$ mortality of $4.9 \%$ is similar to those in other recent trials ${ }^{44,78}$ and might reflect the exclusion of patients with high risk for progressing to critical illness (i.e. those with ferritin levels $>2000 \mu \mathrm{g} / \mathrm{ml}$, white blood cell count above $25.000 / \mu \mathrm{l}$ or mechanical ventilation prior to randomization) and improved outcomes with the current standard of care compared to the beginning of the pandemic. The standard of care for COVID-19 patients changed during the course of this trial especially with regard to the use of glucocorticoids. SARPAC was enrolled in Belgian centers and included mostly white and male patients. This could limit the extrapolation of our findings to different patient populations. 
In conclusion, this translational study from mice to humans with COVID-19 identified inhalation with GM-CSF as a potential therapy for COVID-19 pneumonia, improving blood oxygenation while at the same time boosting antiviral immunity with minimal side effects. 


\section{METHODS}

\section{Mice and treatments}

The following mice were used in this study; female C57BL/6 mice (aged 6-10 weeks) were purchased from Janvier (France); Csf2-/- mice were bred at the animal facility of the VIBUGhent. All animals were housed under specific-pathogen-free conditions in individually ventilated cages in a controlled day-night cycle and given food and water ad libitum. For timed pregnancies, female C57BL/6 mice were injected intraperitoneal with 5 IU serum gonadotropin (Folligon; Intervet) to stimulate follicle growth and 5 IU human chorionic

gonadotropin (Chorulon; Intervet) to induce ovulation. Briefly, neonatal Csf2-/- mice were treated 5 times on the first 5 days of birth with rGM-CSF (5ug GM-CSF in 5 ul BPS per day via i.n. administration $)^{5}$. Negative control mice $=C s f 2^{-/-}$mice treated with PBS (also 5 ul). All animal experiments were approved by the local animal ethics committee (VIB-UGhent) and were performed according to local guidelines and Belgian animal protection law.

\section{Flow cytometry and cell sorting of murine samples}

Cell sorting was performed on a FACSAria II cytometer. After cell sorting, purity was checked (always $>95 \%$ ). For flow cytometry, lungs were cut into small pieces, incubated in RPMI containing Liberase TM (Roche) and DNase (Roche), and then syringed through a 19-gauge needle to obtain a homogenous cell suspension. Red blood cells were lysed for 4 min at room 
temperature in $1 \mathrm{ml}$ osmotic lysis buffer. Cells were sorted exactly as in ${ }^{5}$ (macrophages, preAMs and AMs in WT see Fig.3, GM-CSF treated mice gating see Fig. 6 of ${ }^{5}$ ).

Fluorochrome- or biotin-conjugated mAbs specific for mouse CD11c (clone N418), CD3 (clone 145-2C11), CD19 (clone 1D3), Ly-6G (clone 1A8), CD11b (clone M1/70), CD64 (clone X545/7.1), Ly-6C (clone AL21), SiglecF (clone E50-2440), SAV, Ki-67 (clone B56), Sca-1 (clone d7); the corresponding isotypes; and the secondary reagent PE-Texas red-conjugated streptavidin were all purchased from BD or eBioscience. Anti-MHCII (clone M5/114) and anti-Epcam (clone G8.8) were purchased from BioLegend. Anti-F4/80 (clone A3-1) was purchased from Serotec.

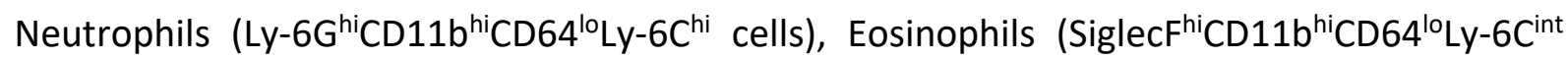
cells), $T$ cells $\left(\mathrm{CD} 3^{\text {hi }} \mathrm{CD} 11 \mathrm{~b}^{\text {lo }} \mathrm{CD} 64^{\text {lo }}\right.$ cells), and $\mathrm{B}$ cells $\left(\mathrm{CD} 1 \mathrm{~g}^{\mathrm{hi}} \mathrm{CD} 11 \mathrm{~b}^{\text {lo }} \mathrm{CD} 64^{\text {lo }}\right.$ cells) were systematically outgated before analysis. Fixable live/dead marker Aqua was purchased from Invitrogen. Dead cells were outgated using the live/marker before analysis.

\section{GM-CSF signature}

To identify the mouse alveolar macrophage (AMF) signature genes that are CSF2 dependent we compared GeneChip Mouse Gene 1.0 ST arrays (Affymetrix) microarrays of GM-CSF KO mice to microarrays covering the AMF development: Yolk Sac MF (E12.5), Fetal liver monocyte (E15.5), Bone Marrow monocyte (adult), lung macrophage on E15.5, E17.5 and E19.5, PreAMF on day of birth, AMF on day 9 after birth and adult AMF. 
The microarrays were analysed using the limma R package ( $v$ 3.42.2). The Robust Multi-array Average (RMA) procedure was used to normalize data within arrays (probeset summarization, background correction and log2-transformation) and between arrays (quantile normalization). Probesets were filtered and converted into gene symbols using the mogene10sttranscriptcluster.db R package ( $v$ 8.7.0).

To identify the AMF signature genes that are CSF2 dependent we first calculated the DE genes between the AMF group and the primitive MF groups combined with the BM_mono and FL_mono. A gene was considered differentially expressed when the Log2fold change $>1$ and the Adjusted Pvalue < 0.05 (limma Bioconductor package (Ritchieet al., 2015), multiple testing correction by the Benjamini-Hochberg method).

In order to only retain the genes with a perfect gene signature, we only kept the DE genes where the (mean normalised expression values in the AMF samples) > (mean normalised expression values in the primitive $\mathrm{MF}$ groups, $\mathrm{BM} \_$mono and $\mathrm{FL}$ _mono samples) +1 . A final filtering was done by only keeping the genes that overlap with our AMF core gene list. The AMF core gene list was obtained by comparing Alveolar Macrophages to Liver Macrophages, Spleen Macrophages, Brain Macrophages, Peritoneal Macrophages and Small Intestine Macrophages. Combat was used to correct for batch effects caused by the different experiments: overlapping samples over the different experiments were used as input for the 'mod' parameter of the ComBat function (sva R package, v3.34.0). For each gene we calculated the mean and median expression in the AMF samples, and the mean and median expression in the other MF samples. Genes that have a mean and median value which is $>1.2$ times higher in the AMF samples compared to the other MF samples, were retained. We next scaled the 
expression values of these genes by calculating the mean expression value per gene over all MF samples, which is then subtracted from each MFs' particular gene expression value. These scaled expression values needed to be positive for every AMF sample and negative for every other MF sample (but 3 mismatches were allowed here) in order to add the gene to the AMF core list. All this resulted in 128 AMF core genes and 22 AMF signature genes that are CSF2 dependent.

To identify the AMF signature genes lacking in GM-CSF KO mice we first calculated the DE genes between MF_Gm_csfKO and AMF group, primitive MF groups, BM_mono and combined. A gene was considered differentially expressed using the same cut offs as described above. In order to only retain the genes with a perfect gene signature, we only kept the $D E$ genes where the (mean normalised expression values in the MF_Gm_csfKO samples) > (mean normalised expression values in the AMF, primitive MF groups, BM_mono and FL_mono samples) + 1. This resulted in 73 AMF signature genes lacking in GM-CSF KO mice.

We next converted the found genes into the human orthologs by looking up the human gene symbol on NCBI (https://www.ncbi.nlm.nih.gov/search/) and checking if there is an ortholog in human listed under the 'Ortholog' tab. The found orthologs were then used as input for the SingleCellSignatureExplorer tool to identify where these genes are enriched in the UMAP.

Human BALF samples and single cell library preparation: 
We profiled matching bronchoalveolar lavage fluid (BALF) from patients who have been hospitalized with COVID-19 ( $n=8)$, non-COVID-19 pulmonary infection $(n=8)$, interstitial lung disease (ILD) ( $n=1)$ and control individuals $(n=2)$. The analysis includes single-cell 3' RNAsequencing along with the quantitative measurement of surface proteins using panels of more than 250 oligo-conjugated antibodies (TotalSeq A - CITEseq). The study population entails adult patients with a diagnostic or therapeutic need for bronchoscopy. Patients aged 18-100 years old were eligible for study inclusion if they had clinical symptoms suggestive of COVID19 and if hospitalization was required. Controls were asymptomatic and were selected from a group of patients requiring a bronchoscopy with BAL for diagnostic work or follow-up of other diseases. In these cases, lavage was always performed in a healthy lung lobe and SARS-CoV-2 was formally ruled-out by RT-PCR. This study was performed in accordance with the principles expressed in the Declaration of Helsinki. Written informed consent was obtained from all patients or a legal representative. The study was approved by the Ethics Committee of Ghent University Hospital (Belgium), AZ Jan Palfijn (Belgium) and AZ Maria Middelares (Belgium), where all samples have been collected. After dimensionality reduction, integration and clustering of the BALF cells, we mapped more than 60 clusters corresponding with immune and epithelial cell identities in our preliminary analysis defined by expression of specific marker genes or antibodies.

Bronchoscopy with BAL was performed bedside using a single use disposable video bronchoscope. Bronchoscopy was only performed in hemodynamically and respiratory stable patients. In spontaneously breathing patients, an additional oxygen need of $3 \mathrm{~L} / \mathrm{min}$ in rest was 
required. Recommended personal protective equipment was used: full face mask, disposable surgical cap, medical protective mask (N95/FFP2/FFP3), work uniform, disposable medical protective gown, disposable gloves. Three to five aliquots of $20 \mathrm{~mL}$ sterile normal saline were instilled into the region of the lung with most aberrations on chest CT. Retrieval was done by suctioning of the scope. BAL fluid was collected in siliconized bottles to prevent cell adherence and kept at $4{ }^{\circ} \mathrm{C}$. BAL fluid was filtered through a $100 \mu \mathrm{m}$ cell strainer (BD Biosciences) and centrifuged for $7 \mathrm{~min}$ at $1300 \mathrm{rpm}$ at $4{ }^{\circ} \mathrm{C}$. The supernatant was removed and the BAL fluid cells were counted and subsequently processed fresh for CITEseq/scRNAseq. One million of cells was used for subsequent single cell RNA sequencing while the remaining cells were frozen in $1 \mathrm{~mL}$ 90\% fetal calf serum (FCS, Sigma), 10\% dimethyl sulphoxide Hybri-Max (DMSO, Sigma) in a cryovial using a $5100 \mathrm{Cryo} 1{ }^{\circ} \mathrm{C}$ Freezing Container (Nalgene) to $-80{ }^{\circ} \mathrm{C}$. Afterwards the cells were stored stored in liquid nitrogen $\left(196^{\circ} \mathrm{C}\right)$. Whole blood was collected in EDTA tube and processed within a maximum of 1.5 hours after collection. Whole blood separation was $\mu$ performed by bringing whole blood, diluted with PBS 7.2 (ThermoFisher Scientific, \# 20012027), in a Leucosep ${ }^{\mathrm{TM}}$ tube, (Greiner Bio-One, \# 227290), prefilled with $15 \mathrm{~mL}$ Lymphoprep ${ }^{\text {TM }}$ (Stemcell technologies, \# 07851), followed by a centrifugation step of 30 minutes at $1500 \mathrm{rpm}$ (acceleration 5, brake 3). After isolation, the PBMCs were twice washed in PBS 7.2 and centrifuged at $350 \mathrm{xg}$ for 10 minutes in a cooled centrifuge at $4^{\circ} \mathrm{C}$. Isolated PBMCs were counted, cryopreserved in $1 \mathrm{~mL}$ FCS/DMSO $10 \%$ and stored in liquid nitrogen $\left(196^{\circ} \mathrm{C}\right)$.

\section{Preprocessing Data}


Single cell sequencing libraries were sequenced with a NovaSEQ S4 flow cell with custom sequencing metrics (single-indexed sequencing run, 28/8/0/98 cycles for R1/i7/i5/R2) (Illumina). Sequencing was performed at the VIB Nucleomics Core (VIB, Leuven).

The demultiplexing of the raw data was performed using CellRanger software $(10 x-$ version 4.0; cellranger mkfastq which wraps Illumina's bcl2fastq). The reads obtained from the demultiplexing were used as the input for 'cellranger count' (CellRanger software), which aligned the reads to a merged human/SARS-CoV-2 genome using STAR and collapses to unique molecular identifier (UMI) counts. In order to maintain explicit control over all gene and cell quality control filters, we used the raw feature-barcode matrix instead of the the filtered feature-barcode matrix generated by CellRanger. As an initial filtering, we removed all cells with less than 200 genes and genes expressed in less than 3 cells.

First, the hashed samples were demultiplexed by allocating cells to a specific donor using a SNP-based algorithm (Kang et al., 2018). Droplets with reads from different donors were omitted from the analysis. We next identified outlier cells based on 3 metrics: library size, number of expressed genes and mitochondrial proportion. All cells that were 5 median absolute deviation (MADs) higher or lower than the median value for each metric were removed. Cells that expressed less than 200 genes - if still present - were removed. Genes expressed in less than 50 cells were discarded. For the antibodies (ABs) we selected the top 120 most expressed ABs. We subsequently used this data as input for the TotalVI model (scvi Python package v0.6.7) (Gayoso et al., 2021). The BAL dataset contains 19 samples of which 
16 samples are CITE-Seq samples. We analyzed this dataset using the 'Integration of CITE-seq and scRNA-seq data with totalVI' workflow as described on http://docs.scvi-tools.org/.

The UMAP was checked for contamination cells, doublets and other unwanted cells, such as cells with high $A B$ counts, cells with lower nGenes ... After multiple rounds of cleaning a final UMAP was obtained on which we calculated the DE genes and DE proteins using the scvi Python package. A gene was considered differential expressed when 'Ifc_median' > 1.0, 'bayes_factor' > 1 and 'non_zeros_proportion1' > 0.10. An antibody was considered differential expressed when $p$ proba_de' $\quad 0.05$ and '(raw_mean1/raw_mean2*Ifc_mean) $>=0.2$ '.

Heatmaps were made by scaling the normalized values (denoised values; calculated by the TotalVI workflow) using the scale_quantile function of the SCORPIUS R package (v1.0.7) and the pheatmap R package (v1.0.12). The plots showing the expression of certain genes or proteins were created based on the normalized values (denoised values) using a quantile cutoff of 0.95 and via the scanpy.pl.umap function of the Scanpy Python package (v1.5.1).

The diffusion map was created using the scanpy.tl.diffmap function of the Python Scanpy package (v1.5.1). Slingshot was applied on the first three diffusion components together the annotated clusters using the slingshot R package (v1.4.0). The Monocyte cluster was used as the starting point of the trajectory.

Trial design, SARPAC participants and randomization 
We conducted a randomized controlled, multi-center, open-label, interventional study across 5 hospitals in Belgium. Eligible patients were adults (18-80 years of age) with confirmed recent COVID-19 pneumonia (i.e. positive polymerase-chain reaction (PCR) assay, antigen detection test or serology $<2$ weeks prior to randomization) and acute respiratory failure defined as a ratio of the partial arterial pressure of oxygen to the fraction of inspired oxygen $\left(\mathrm{PaO}_{2} / \mathrm{FiO}_{2}\right)$ below $350 \mathrm{mmHg}$ or blood oxygen saturation level $\left(\mathrm{SpO}_{2}\right)$ below 93\% on minimal $2 \mathrm{~L} / \mathrm{min}$ supplemental oxygen. Patients were excluded from the trial in case of (1) known serious allergic reactions to yeast-derived products, (2) lithium carbonate therapy, (3) mechanical ventilation prior to randomization, (4) peripheral white blood cell count above $25.000 / \mu \mathrm{L}$ and/or active myeloid malignancy, (5) high dose systemic steroid therapy (> $20 \mathrm{mg}$ methylprednisolone or equivalent) for a COVID-19-unrelated disorder, (6) enrolment in another investigational study, (7) pregnant or breastfeeding or (8) ferritin levels $>2000 \mu \mathrm{g} / \mathrm{mL}$ (which will exclude ongoing CRS). The full list of in- and exclusion criteria can be found in the study protocol (Extended Data). All patients received standard of care validated th that time (e.g. anti-viral treatment, glucocorticoids and supportive care). However, concomitant treatment with another investigational agent was prohibited.

Eligible patients were randomly assigned in a 1:1 ratio to receive sargramostim $125 \mu \mathrm{g}$ twice daily for 5 days as a nebulized inhalation on top of standard of care (active group), or to receive standard of care treatment (control group). Upon progression of disease requiring initiation of non-invasive or invasive mechanical ventilatory support within the 5-day period, in patients in the active group, inhaled sargramostim is replaced by intravenous sargramostim $125 \mathrm{\mu g} / \mathrm{m}^{2}$ body surface area once daily until the 5-day period is reached. Randomization and subsequent 
data collection were done using REDCap ${ }^{79}$. The primary analysis was performed at day 6 or hospital discharge whichever came first. The final trial visit occurred 10-20 weeks after randomization.

\section{Procedures and concomitant standard of care treatment}

Enrolled patients underwent multiple daily evaluations. Additional serum and EDTA samples and arterial blood gas samples were collected on day 1 and 6 since randomization and on follow-up (10-20 weeks after randomization). The majority of patients randomized before July 2020 received hydroxychloroquine as per standard of care and the majority of patients randomized from July 2020 onwards received dexamethasone as per standard of care.

\section{Outcomes}

The primary endpoint was the improvement in oxygenation after 5 days of sargramostim treatment and/or standard of care. Oxygenation was assessed by the $\mathrm{PaO}_{2} / \mathrm{FiO}_{2}$ ratio and $\mathrm{P}(\mathrm{A}-$ a) $\mathrm{O}_{2}$ gradient. Median change from baseline in oxygenation to day 6 and the numbers of patients that experienced at least $25 \%, 33 \%$ and $50 \%$ improvement in oxygenation were analyzed in the sargramostim group and the usual care group.

Supportive secondary endpoints included amongst others: time to clinical improvement; length of hospital stay; time until progression to mechanical ventilation and/or ARDS. For patients of selected sites, additional blood samples were collected to measure specific 
immunological parameters. All supportive and secondary endpoints are listed in the statistical analysis plan, which can be found in the extended data supplement.

Key safety endpoints included all-cause mortality, serious adverse events, sepsis and septic shock during hospital stay. Adverse events were recorded according to the system organ class and preferred terms in the Common Terminology Criteria for Adverse Events, version 6.0.

\section{Sample collection and processing}

Peripheral venous blood specimens were collected from healthy individuals and study patients using simultaneously obtained EDTA and serum tubes. Healthy individuals were age, BMI and sex matched without prior medical history and in the absence of recent infection or vaccination (<6 weeks). Healthy controls provided written informed consent prior to blood sampling and storage of their samples in the PID biobank (EC Ghent University Hospital 2012/593). EDTA blood was diluted 1:2 in Hank's Balanced Salt Solution (HBSS; Fisher Scientific; 24020117) and peripheral blood mononuclear cells (PBMCs) isolated after gradient centrifugation over Ficoll-Paque (GE Healthcare; 17-1440-02). Cell free plasma was subsequently transferred from the supernatant, aliquoted and stored at $-80^{\circ} \mathrm{C}$. After two washings in cold HBSS, the yielded layer of PBMCs was counted in a Neubauer plate with trypan blue exclusion of dead cells. PBMCs were aliquoted in 90\% Fetal Calf Serum (FCS; Sigma Aldrich; F7524) and 10\% dimethyl sulfoxide (DMSO; Sigma Aldrich; D2650). Vials were placed in a $-80^{\circ} \mathrm{C}$ freezer using controlled rate freezing in preparation for final storage at $-150^{\circ} \mathrm{C}$ until 
further use. Serum tubes were spun at $4^{\circ} \mathrm{C}$ and cell free serum was subsequently aliquoted and stored at $-80^{\circ} \mathrm{C}$ until analysis.

\section{Extended immunophenotyping on PBMCs}

Cryopreserved PBMCs were thawed in $37^{\circ} \mathrm{C}$ preheated complete medium (RPMI-1640 medium supplemented with GlutaMAX, 10\% FCS, 1\% penicillin-streptomycin (Pen/Strep; 10,000 U/mL; Gibco; 15140122), 1 mM sodium pyruvate (Gibco; 11360070), 1\% non-essential amino acids (NEAA; Gibco; 11140035) and 50 M 2-mercaptoethanol (Gibco; 31350010). Cells were left to recuperate for $30 \mathrm{~min}$ at $37^{\circ} \mathrm{C}$ and $5 \% \mathrm{CO} 2$ after removal of DMSO. Cells were counted using Luna-FX7 (Logos Biosystem) and $4^{*} 10^{\wedge} 6$ cells were plated for immunophenotyping. Next, cells were first stained with FcR block (Biolegend; 422302) together with Mono Block (Biolegend; 426102), biotin conjugated antibodies and Fixable Viability dye efluor 506 (Thermofisher; 65-0866-14) in PBS. In a second step, remaining surface markers were stained with a mixture of antibodies in FACS buffer (DPBS pH7.4, 1\% Bovine Serum Albumin, 0,05\% NaN3, 1 mM EDTA) and Brilliant Stain buffer (BD Biosciences). Cells were fixed, permeabilized and intracellular stained with antibodies using FoxP3 staining buffer (Thermofisher; 00-5523-00) following manufacturer's protocol. Acquisition and analysis of labeled cell suspensions was performed with a FACSymphony flow cytometer (BD biosciences) and subsequent analysis of data with FlowJo10 software (BD biosciences). Antibodies used to define PBMC populations can be found in extended data table 1. 


\section{T cell restimulation and FluoroSpot}

To quantify SARS-CoV2 specific CD4 and CD8 T cells, peptide restimulation with Fluorospot for IFN $\gamma$ and IL-2 was performed (Mabtech; Fluorospot Flex). In short, 2,5X10^5 PBMC were resuspended in complete medium, plated in triplicate into 96 well plates with a PVDF membrane bottom layer, precoated overnight with capturing antibodies directed against IFN $\gamma$ and IL-2. PBMC were stimulated with CD4 T cell (CD4-R and CD4-S MP) or CD8 T cell (CD8-A and CD8-B MP) specific peptide pools at a final concentration of $1 \mu \mathrm{g} / \mathrm{mL}$, as described ${ }^{55}$. After 23 hours of stimulation, plates were collected and spots were developed following manufacturer's protocol (Mabtech, FSP-0102-10). Spots were revealed and quantified using Mabtech IRIS Fluorospot reader (Mabtech).

\section{Biomarker quantification}

Serum cytokines IL-1 $\beta$, IL-1Ra, IL-6, IL-8 (CXCL8), IL-10, IL-18, CXCL9, CXCL10, TNF $\alpha$, MCP-1 (CCL2), were quantified in duplicate by magnetic bead-based multiplex assay using XMAP technology (Luminex Corporation) and Bio-Plex assays, kits and standards (Human Cytokine Screening Panel \#12007919; Bio-Rad, and Human Inflammation Panel \#171DL0001; Bio-Rad) according to manufacturer's protocol. Multiplex assay samples were diluted at 1:2. Acquisition and analysis was performed on a Bio-Plex 200 reader and using the Bio-Plex Manager software (Bio-Rad).

\section{C5a measurement}


Complement components were measured in cell free plasma. C5a was measured using customizable enzyme immunoassay multiplex kits (MicroVue Complement Multiplex, Quidel; A905s), according to manufacturer's instructions. Data were acquired on a Q-View Imager LS, using the Q-View Software 3.11.

\section{Immunoglobulin ELISA}

SARS-CoV2 antibodies on stored serum samples of included patients were analyzed with antigen-coated ELISA kits (EUROIMMUN AG) for anti-spike 1 (S1) IgA (EI 2606-9601 A) and IgG (EI 2606-9601 G) and anti-nucleocapsid protein (NCP) IgG (EI 2606-9601-2 G), according to manufacturer's protocol.

\section{Trial oversight and role of the funder}

The trial was approved by the competent authorities and the Ethical Committee of Ghent University Hospital, and the trial was conducted in accordance with Good Clinical Practice guidelines and the Declaration of Helsinki. Bart N. Lambrecht designed the trial and was the coordinating investigator. An independent data safety monitoring board monitored participant safety. Every patient or their legal representative provided informed consent for participation. All investigators take responsibility for the integrity of the trial and the publication. The first authors wrote the first draft of the manuscript. All authors made the decision to submit the manuscript for publication and vouch for the accuracy and completeness of the data and for the fidelity of the trial to the protocol. 


\section{Sample calculation and power analysis}

The target difference is the difference from baseline measured at the primary endpoint (at day 6) between the control and the treated group. Given a sample size of 40 patients on each treatment, a minimal improvement of $10 \%$ in the treated group relative to the control group will be detected as significant at a significance level of 0.01 with a power of 0.90 . The error variance was set at 100 units, corresponding with a standard deviation of 10 units. Sample calculation and power analysis were performed using Genstat.

\section{Statistical analysis}

All efficacy endpoints were analyzed in the intention-to-treat analysis which included all patients who had undergone randomization. Patients with missing data (i.e. no arterial blood gas analysis at baseline and/or day 6) were excluded from the analyses for which the missing data are necessary. Patients with a negative $\mathrm{P}(\mathrm{A}-\mathrm{a}) \mathrm{O}_{2}$ gradient were excluded for oxygenation analyses, given these values are biologically not possible.

The number of patients that experienced at least $25 \%, 33 \%$ and $50 \%$ improvement in oxygenation was compared between the sargramostim group and the standard of care group by a Chi-square test. The median change from baseline in oxygenation to day 6 was analyzed by a Brown-Mood test. P values were two sided, and any P value less than 0.05 was considered statistically significant. Number of subjects is indicated as "n." Statistical details of 
experiments can be found in the figure legends. The complete SAP is provided in the Supplementary Appendix.

Safety data were analyzed descriptively in the safety population which included all patients that received at least one dose of sargramostim on the active arm and all patients who received only standard of care on the control arm. All 


\section{Authors contribution}

B.N.L. conceptualized the study design, designed and filed the study protocol to competent authorities and takes full responsibility for data integrity. C.B., E.D.L., K.V.D, J.D., B.M recruited patients in the trial, collected patients samples and data and contributed in drafting the manuscript. S.J.V., I.K.D., S.A., H.S., Y.V.W. E.V.B., P.D. recruited patients in various centers. T.M. performed bronchoscopies. M.G. J.D. N.D. performed the mice experiments addressing role of GM-CSF. M.G. and N.V. developed the CITEseq protocols. L.M. and M.G. performed the Bio-IT analysis of the murine microarray and human CITEseq data. V.B., L.H., L.N., F.H. and S.J.T. performed and analyzed the experiments concerning the immunological parameters and biomarkers. J.D.C. and L.V. shared raw BAL data of healthy controls and patients with COVID19 and non-COVID-19 pulmonary infection. D.W. and A.S. provided the SARS-CoV-2 peptide pools and protocols for T cell restimulation. B.N.L., S.J.T and M.G. critically analyzed data, and wrote the manuscript. All authors revised the manuscript.

\section{Funding}

Ghent University Hospital provided trial resources. Partner Therapeutics LLC (Lexington, MA) provided the study medication sargramostim (Leukine ${ }^{\circledR}$ ). The Ghent University Special Research Fund (BOF) supported the clinical follow up of patients at Ghent University Hospital (UZ Gent). Additional funding for biomarker analysis was provided by the VIB Grand Challenges program (Flanders Institute for Biotechnology) and by an unrestricted research grant from Partner Therapeutics. The single-cell CITE-seq profiling of BALF cells was funded 
through the Chan Zuckerberg Initiative (CZI) "Covid-Track" and the "Covid-Trace" projects; BOFCOV (COV046-20); and FWO COV (GOG4520N). This work was funded by NIH contract Nr. 75N9301900065 (D.W., A.S.).

\section{Acknowledgements}

The authors acknowledge professional support and committed efforts from various organizations and individuals involved in this trial. The clinical trial team of Department of Respiratory Medicine at UZ Gent was involved in protocol development, amendment filing and eCRF construction. Health Innovation \& Research Institute of UZ Gent (HIRUZ) was involved in eCRF design, protocol design, EC reporting, drug dispensing, trial monitoring, data cleaning and sponsor site management. The hospital pharmacy of UZ Gent dispensed drugs and nebulizers to all study sites. The authors thank Veronique De Backer, Nancy Cabooter, Kim Deswarte, Declercq Zara, Justine Van Moorleghem, Roanne Schuppers, Helena Flipts, Lisa Roels, Karlien Claes, Helena Aegerter, Ursula Smole, Leen Seys and Dorine Sichien for the PBMC isolation. The authors wish to express their gratitude to the members of the Data Monitoring and Safety Committee and all clinicians involved in patient recruitment at the different participating sites. We thank the IRC-VIB Flow core facility for assistance, VIB Tech Watch and the VIB Single-cell accelerator program for their help benchmarking single-cell technologies such as CITE-Seq.

\section{Competing interests}


A.S. is a consultant for Gritstone, Flow Pharma, Arcturus, Immunoscape, CellCarta, OxfordImmunotech and Avalia. LI has filed for patent protection for various aspects of T cell epitope and vaccine design work. All other authors declare no conflict of interest. D.F.R. is an employee of and have stock options in Partner Therapeutics.

\section{Data sharing statement}

The sc-RNA and CiteSeq data from the COVID-19 patients are publicly available online via singularity portal of the Flemish institute for Biotechnology (VIB) via the COVID-19 response link (https://www.single-cell.be/covid19/browser). De-identified individual participant data will be available upon approval of a proposal. The shared data can be used for the analyses

mentioned in the approved proposal. Proposals should be directed to bart.lambrecht@ugent.be (corresponding author) 


\section{References}

1. Westphalen K, Gusarova GA, Islam MN, et al. Sessile alveolar macrophages communicate with alveolar epithelium to modulate immunity. Nature. Feb 27 2014;506(7489):503-6. doi:10.1038/nature12902

2. Neupane AS, Willson M, Chojnacki AK, et al. Patrolling Alveolar Macrophages Conceal Bacteria from the Immune System to Maintain Homeostasis. Cell. Oct 1 2020;183(1):110-125 e11. doi:10.1016/j.cell.2020.08.020

3. Hussell T, Bell TJ. Alveolar macrophages: plasticity in a tissue-specific context. Nat Rev Immunol. Feb 2014;14(2):81-93. doi:10.1038/nri3600

4. Yoshida M, Ikegami M, Reed JA, Chroneos ZC, Whitsett JA. GM-CSF regulates protein and lipid catabolism by alveolar macrophages. Am J Physiol Lung Cell Mol Physiol. Mar 2001;280(3):L379-86. doi:10.1152/ajplung.2001.280.3.L379

5. Guilliams M, De Kleer I, Henri S, et al. Alveolar macrophages develop from fetal monocytes that differentiate into long-lived cells in the first week of life via GM-CSF. J Exp Med. Sep 23 2013;210(10):1977-92. doi:10.1084/jem.20131199

jem.20131199 [pii] 
6. Gschwend J, Sherman SPM, Ridder F, et al. Alveolar macrophages rely on GM-CSF from alveolar epithelial type 2 cells before and after birth. J Exp Med. Oct 4 2021;218(10)doi:10.1084/jem.20210745

7. Schneider C, Nobs SP, Kurrer M, Rehrauer H, Thiele C, Kopf M. Induction of the nuclear receptor PPAR-gamma by the cytokine GM-CSF is critical for the differentiation of fetal monocytes into alveolar macrophages. Nat Immunol. Nov 2014;15(11):1026-37. doi:10.1038/ni.3005

8. Suzuki T, Sakagami T, Rubin BK, et al. Familial pulmonary alveolar proteinosis caused by mutations in CSF2RA. J Exp Med. Nov 24 2008;205(12):2703-10.

doi:10.1084/jem.20080990

9. Tazawa R, Ueda T, Abe M, et al. Inhaled GM-CSF for Pulmonary Alveolar Proteinosis. N Engl J Med. Sep 5 2019;381(10):923-932. doi:10.1056/NEJMoa1816216

10. Hashimoto D, Chow A, Noizat C, et al. Tissue-resident macrophages self-maintain locally throughout adult life with minimal contribution from circulating monocytes. Immunity. Apr 18 2013;38(4):792-804. doi:10.1016/j.immuni.2013.04.004 S1074-7613(13)00157-X [pii]

11. Yona S, Kim KW, Wolf $\mathrm{Y}$, et al. Fate mapping reveals origins and dynamics of monocytes and tissue macrophages under homeostasis. Immunity. Jan 24 2013;38(1):79-91. doi:10.1016/j.immuni.2012.12.001

S1074-7613(12)00548-1 [pii]

12. Bittmann I, Dose T, Baretton GB, et al. Cellular chimerism of the lung after transplantation. An interphase cytogenetic study. Am J Clin Pathol. 2001;115(4):525-33. 
13. Byrne AJ, Powell JE, O'Sullivan BJ, et al. Dynamics of human monocytes and airway macrophages during healthy aging and after transplant. J Exp Med. Mar 2 2020;217(3)doi:10.1084/jem.20191236

14. Nayak DK, Zhou F, Xu M, et al. Long-Term Persistence of Donor Alveolar Macrophages in Human Lung Transplant Recipients That Influences Donor-Specific Immune Responses. Am J Transplant. Aug 2016;16(8):2300-11. doi:10.1111/ajt.13819

15. Aegerter H, Kulikauskaite J, Crotta S, et al. Influenza-induced monocyte-derived alveolar macrophages confer prolonged antibacterial protection. Nat Immunol. Feb 2020;21(2):145-157. doi:10.1038/s41590-019-0568-x

16. Machiels B, Dourcy M, Xiao X, et al. A gammaherpesvirus provides protection against allergic asthma by inducing the replacement of resident alveolar macrophages with regulatory monocytes. Nat Immunol. Oct 16 2017;doi:10.1038/ni.3857

17. Guan WJ, Ni ZY, Hu Y, et al. Clinical Characteristics of Coronavirus Disease 2019 in China. N Engl J Med. Feb 28 2020;doi:10.1056/NEJMoa2002032

18. Vabret N, Britton GJ, Gruber C, et al. Immunology of COVID-19: Current State of the Science. Immunity. Jun 16 2020;52(6):910-941. doi:10.1016/j.immuni.2020.05.002

19. Gu SX, Tyagi T, Jain K, et al. Thrombocytopathy and endotheliopathy: crucial contributors to COVID-19 thromboinflammation. Nat Rev Cardiol. Mar 2021;18(3):194-209. doi:10.1038/s41569-020-00469-1

20. Dorward DA, Russell CD, Um IH, et al. Tissue-Specific Immunopathology in Fatal COVID-19. Am J Respir Crit Care Med. Jan 15 2021;203(2):192-201.

doi:10.1164/rccm.202008-32650C 
21. Merad M, Martin JC. Pathological inflammation in patients with COVID-19: a key role for monocytes and macrophages. Nat Rev Immunol. Jun 2020;20(6):355-362.

doi:10.1038/s41577-020-0331-4

22. Stephenson E, Reynolds G, Botting RA, et al. Single-cell multi-omics analysis of the immune response in COVID-19. Nat Med. May 2021;27(5):904-916. doi:10.1038/s41591021-01329-2

23. Xu Z, Shi L, Wang Y, et al. Pathological findings of COVID-19 associated with acute respiratory distress syndrome. Lancet Respir Med. Apr 2020;8(4):420-422. doi:10.1016/S2213-2600(20)30076-X

24. Del Valle DM, Kim-Schulze $\mathrm{S}$, Huang $\mathrm{HH}$, et al. An inflammatory cytokine signature predicts COVID-19 severity and survival. Nat Med. Oct 2020;26(10):1636-1643.

doi:10.1038/s41591-020-1051-9

25. Mehta P, McAuley DF, Brown M, et al. COVID-19: consider cytokine storm syndromes and immunosuppression. Lancet. Mar 28 2020;395(10229):1033-1034. doi:10.1016/S01406736(20)30628-0

26. Lucas C, Wong P, Klein J, et al. Longitudinal analyses reveal immunological misfiring in severe COVID-19. Nature. Aug 2020;584(7821):463-469. doi:10.1038/s41586-020-2588-y 27. Wauters $E$, Van Mol P, Garg AD, et al. Discriminating mild from critical COVID-19 by innate and adaptive immune single-cell profiling of bronchoalveolar lavages. Cell Res. Mar 2021;31(3):272-290. doi:10.1038/s41422-020-00455-9

28. Bost P, Giladi A, Liu Y, et al. Host-Viral Infection Maps Reveal Signatures of Severe COVID-19 Patients. Cell. Jun 25 2020;181(7):1475-1488 e12. doi:10.1016/j.cell.2020.05.006 
29. Bost $P$, De Sanctis $F$, Cane $S$, et al. Deciphering the state of immune silence in fatal COVID-19 patients. Nat Commun. Mar 5 2021;12(1):1428. doi:10.1038/s41467-021-21702-6 30. Liao M, Liu Y, Yuan J, et al. Single-cell landscape of bronchoalveolar immune cells in patients with COVID-19. Nat Med. Jun 2020;26(6):842-844. doi:10.1038/s41591-020-0901-9 31. Zhao Y, Kilian C, Turner JE, et al. Clonal expansion and activation of tissue-resident memory-like Th17 cells expressing GM-CSF in the lungs of severe COVID-19 patients. Sci Immunol. Feb 23 2021;6(56)doi:10.1126/sciimmunol.abf6692

32. Vanderbeke L, Van Mol P, Van Herck Y, et al. Monocyte-driven atypical cytokine storm and aberrant neutrophil activation as key mediators of COVID-19 disease severity. Nat Commun. Jul 5 2021;12(1):4117. doi:10.1038/s41467-021-24360-w

33. Chua RL, Lukassen S, Trump S, et al. COVID-19 severity correlates with airway epithelium-immune cell interactions identified by single-cell analysis. Nature biotechnology. Aug 2020;38(8):970-979. doi:10.1038/s41587-020-0602-4

34. Sacchi A, Grassi G, Bordoni V, et al. Early expansion of myeloid-derived suppressor cells inhibits SARS-CoV-2 specific T-cell response and may predict fatal COVID-19 outcome. Cell death \& disease. Oct 27 2020;11(10):921. doi:10.1038/s41419-020-03125-1

35. Grant RA, Morales-Nebreda L, Markov NS, et al. Circuits between infected macrophages and T cells in SARS-CoV-2 pneumonia. Nature. Feb 2021;590(7847):635-641. doi:10.1038/s41586-020-03148-w

36. Bosteels C, Maes B, Van Damme K, et al. Sargramostim to treat patients with acute hypoxic respiratory failure due to COVID-19 (SARPAC): A structured summary of a study protocol for a randomised controlled trial. Trials. Jun 5 2020;21(1):491. doi:10.1186/s13063020-04451-7 
37. Stoeckius M, Hafemeister C, Stephenson W, et al. Simultaneous epitope and transcriptome measurement in single cells. Nat Methods. Sep 2017;14(9):865-868. doi:10.1038/nmeth.4380

38. Hao Y, Hao S, Andersen-Nissen E, et al. Integrated analysis of multimodal single-cell data. Cell. Jun 24 2021;184(13):3573-3587 e29. doi:10.1016/j.cell.2021.04.048

39. Gayoso A, Steier Z, Lopez R, et al. Joint probabilistic modeling of single-cell multiomic data with totalVI. Nat Methods. Mar 2021;18(3):272-282. doi:10.1038/s41592-02001050-x

40. Street K, Risso D, Fletcher RB, et al. Slingshot: cell lineage and pseudotime inference for single-cell transcriptomics. BMC Genomics. Jun 19 2018;19(1):477. doi:10.1186/s12864018-4772-0

41. van de Laar L, Saelens W, De Prijck S, et al. Yolk Sac Macrophages, Fetal Liver, and Adult Monocytes Can Colonize an Empty Niche and Develop into Functional Tissue-Resident Macrophages. Immunity. Apr 19 2016;44(4):755-68. doi:10.1016/j.immuni.2016.02.017

42. Gautier EL, Shay T, Miller J, et al. Gene-expression profiles and transcriptional regulatory pathways that underlie the identity and diversity of mouse tissue macrophages. Nat Immunol. Sep 30 2012;doi:10.1038/ni.2419

43. WHOReactGroup, Shankar-Hari M, Vale CL, et al. Association Between Administration of IL-6 Antagonists and Mortality Among Patients Hospitalized for COVID-19: A Metaanalysis. JAMA. Jul 6 2021;doi:10.1001/jama.2021.11330

44. Kyriazopoulou E, Poulakou G, Milionis H, et al. Early treatment of COVID-19 with anakinra guided by soluble urokinase plasminogen receptor plasma levels: a double-blind, randomized controlled phase 3 trial. Nat Med. Sep 3 2021;doi:10.1038/s41591-021-01499-z 
45. Thwaites RS, Sanchez Sevilla Uruchurtu A, Siggins MK, et al. Inflammatory profiles across the spectrum of disease reveal a distinct role for GM-CSF in severe COVID-19. Sci Immunol. Mar 10 2021;6(57)doi:10.1126/sciimmunol.abg9873

46. Lang FM, Lee KM, Teijaro JR, Becher B, Hamilton JA. GM-CSF-based treatments in COVID-19: reconciling opposing therapeutic approaches. Nat Rev Immunol. Aug 2020;20(8):507-514. doi:10.1038/s41577-020-0357-7

47. Ma L, Kulkarni AJ. Increased complement activation is a distinctive feature of severe SARS-CoV-2 infection. Sci Immunol. May 13 2021;6(59)doi:10.1126/sciimmunol.abh2259 48. Carvelli J, Demaria O, Vely F, et al. Association of COVID-19 inflammation with activation of the C5a-C5aR1 axis. Nature. Dec 2020;588(7836):146-150. doi:10.1038/s41586020-2600-6

49. Morrissey SM, Geller AE, Hu X, et al. A specific low-density neutrophil population correlates with hypercoagulation and disease severity in hospitalized COVID-19 patients. JCI Insight. May 10 2021;6(9)doi:10.1172/jci.insight.148435

50. Giamarellos-Bourboulis EJ, Netea MG, Rovina N, et al. Complex Immune Dysregulation in COVID-19 Patients with Severe Respiratory Failure. Cell Host Microbe. Jun 10 2020;27(6):992-1000 e3. doi:10.1016/j.chom.2020.04.009

51. Rosler B, Herold S. Lung epithelial GM-CSF improves host defense function and epithelial repair in influenza virus pneumonia-a new therapeutic strategy? Mol Cell Pediatr. Dec 2016;3(1):29. doi:10.1186/s40348-016-0055-5

52. Unkel B, Hoegner K, Clausen BE, et al. Alveolar epithelial cells orchestrate DC function in murine viral pneumonia. J Clin Invest. Oct 2012;122(10):3652-64. doi:10.1172/JCI62139 
53. GM-CSF Controls Nonlymphoid Tissue Dendritic Cell Homeostasis but Is Dispensable for the Differentiation of Inflammatory Dendritic Cells, 6 (2012). Jul.

\section{http://linkinghub.elsevier.com/retrieve/pii/S1074761312002464}

54. Grifoni A, Sidney J, Vita R, et al. SARS-CoV-2 human T cell epitopes: Adaptive immune response against COVID-19. Cell Host Microbe. Jul 14 2021;29(7):1076-1092. doi:10.1016/j.chom.2021.05.010

55. Weiskopf D, Schmitz KS, Raadsen MP, et al. Phenotype and kinetics of SARS-CoV-2specific T cells in COVID-19 patients with acute respiratory distress syndrome. Sci Immunol. Jun 26 2020;5(48)doi:10.1126/sciimmunol.abd2071

56. Huffman JA, Hull WM, Dranoff G, Mulligan RC, Whitsett JA. Pulmonary epithelial cell expression of GM-CSF corrects the alveolar proteinosis in GM-CSF-deficient mice. J Clin Invest. Feb 1 1996;97(3):649-55. doi:10.1172/JCI118461

57. Overgaard CE, Schlingmann B, Dorsainvil White S, et al. The relative balance of GMCSF and TGF-beta1 regulates lung epithelial barrier function. Am J Physiol Lung Cell Mol Physiol. Jun 15 2015;308(12):L1212-23. doi:10.1152/ajplung.00042.2014

58. Matute-Bello G, Liles WC, Radella F, 2nd, et al. Modulation of neutrophil apoptosis by granulocyte colony-stimulating factor and granulocyte/macrophage colony-stimulating factor during the course of acute respiratory distress syndrome. Crit Care Med. Jan 2000;28(1):1-7. doi:10.1097/00003246-200001000-00001

59. Liao HH, Wang YC, Chen MC, et al. Down-regulation of granulocyte-macrophage colony-stimulating factor by 3C-like proteinase in transfected A549 human lung carcinoma cells. BMC Immunol. Feb 17 2011;12:16. doi:10.1186/1471-2172-12-16 
60. De Alessandris S, Ferguson GJ, Dodd AJ, et al. Neutrophil GM-CSF receptor dynamics in acute lung injury. J Leukoc Biol. Jun 2019;105(6):1183-1194. doi:10.1002/JLB.3MA0918$347 R$

61. Sturrock A, Vollbrecht T, Mir-Kasimov M, McManus M, Wilcoxen SE, Paine R, 3rd. Mechanisms of suppression of alveolar epithelial cell GM-CSF expression in the setting of hyperoxic stress. Am J Physiol Lung Cell Mol Physiol. Mar 2010;298(3):L446-53. doi:10.1152/ajplung.00161.2009

62. Tazawa R, Hamano E, Arai T, et al. Granulocyte-macrophage colony-stimulating factor and lung immunity in pulmonary alveolar proteinosis. Am J Respir Crit Care Med. May 15 2005;171(10):1142-9. doi:10.1164/rccm.200406-716OC

63. Tazawa R, Trapnell BC, Inoue Y, et al. Inhaled granulocyte/macrophage-colony stimulating factor as therapy for pulmonary alveolar proteinosis. Am J Respir Crit Care Med. Jun 15 2010;181(12):1345-54. doi:10.1164/rccm.200906-09780C

64. Tazawa $R$, Inoue $Y$, Arai $T$, et al. Duration of benefit in patients with autoimmune pulmonary alveolar proteinosis after inhaled granulocyte-macrophage colony-stimulating factor therapy. Chest. Apr 2014;145(4):729-737. doi:10.1378/chest.13-0603

65. Tobin MJ, Jubran A, Laghi F. P aO2 /F IO2 ratio: the mismeasure of oxygenation in COVID-19. Eur Respir J. Mar 2021;57(3)doi:10.1183/13993003.00274-2021

66. Gowda MS, Klocke RA. Variability of indices of hypoxemia in adult respiratory distress syndrome. Crit Care Med. Jan 1997;25(1):41-5. doi:10.1097/00003246-199701000-00010 67. Herold S, Hoegner K, Vadasz I, et al. Inhaled granulocyte/macrophage colonystimulating factor as treatment of pneumonia-associated acute respiratory distress 
syndrome. Am J Respir Crit Care Med. Mar 1 2014;189(5):609-11. doi:10.1164/rccm.2013112041LE

68. Presneill JJ, Harris T, Stewart AG, Cade JF, Wilson JW. A randomized phase II trial of granulocyte-macrophage colony-stimulating factor therapy in severe sepsis with respiratory dysfunction. Am J Respir Crit Care Med. Jul 15 2002;166(2):138-43.

doi:10.1164/rccm.2009005

69. Paine R, 3rd, Standiford TJ, Dechert RE, et al. A randomized trial of recombinant human granulocyte-macrophage colony stimulating factor for patients with acute lung injury. Crit Care Med. Jan 2012;40(1):90-7. doi:10.1097/CCM.0b013e31822d7bf0

70. Sturrock A, Seedahmed E, Mir-Kasimov M, Boltax J, McManus ML, Paine R, 3rd. GMCSF provides autocrine protection for murine alveolar epithelial cells from oxidant-induced mitochondrial injury. Am J Physiol Lung Cell Mol Physiol. Feb 1 2012;302(3):L343-51. doi:10.1152/ajplung.00276.2011

71. Huang FF, Barnes PF, Feng Y, et al. GM-CSF in the lung protects against lethal influenza infection. Am J Respir Crit Care Med. Jul 15 2011;184(2):259-68.

doi:10.1164/rccm.201012-20360C

72. Subramaniam R, Barnes PF, Fletcher K, et al. Protecting against post-influenza bacterial pneumonia by increasing phagocyte recruitment and ROS production. J Infect Dis. Jun 1 2014;209(11):1827-36. doi:10.1093/infdis/jit830

73. Zhou R, To KK, Wong YC, et al. Acute SARS-CoV-2 Infection Impairs Dendritic Cell and T Cell Responses. Immunity. Oct 13 2020;53(4):864-877 e5. doi:10.1016/j.immuni.2020.07.026 
74. Mehta P, Porter JC, Manson JJ, et al. Therapeutic blockade of granulocyte macrophage colony-stimulating factor in COVID-19-associated hyperinflammation: challenges and opportunities. Lancet Respir Med. Aug 2020;8(8):822-830. doi:10.1016/S2213-2600(20)30267-8

75. Sterner RM, Sakemura R, Cox MJ, et al. GM-CSF inhibition reduces cytokine release syndrome and neuroinflammation but enhances CAR-T cell function in xenografts. Blood. Feb 14 2019;133(7):697-709. doi:10.1182/blood-2018-10-881722

76. Temesgen Z, Burger CD, Baker J, et al. Lenzilumab Efficacy and Safety in Newly Hospitalized Covid-19 Subjects: Results from the Live-Air Phase 3 Randomized Double-Blind Placebo-Controlled Trial. medRxiv. May 5 2021;doi:10.1101/2021.05.01.21256470

77. Cremer PC, Abbate A, Hudock K, et al. Mavrilimumab in patients with severe COVID19 pneumonia and systemic hyperinflammation (MASH-COVID): an investigator initiated, multicentre, double-blind, randomised, placebo-controlled trial. Lancet Rheumatol. Jun 2021;3(6):e410-e418. doi:10.1016/S2665-9913(21)00070-9

78. Guimaraes PO, Quirk D, Furtado RH, et al. Tofacitinib in Patients Hospitalized with Covid-19 Pneumonia. N Engl J Med. Jul 29 2021;385(5):406-415. doi:10.1056/NEJMoa2101643

79. Harris PA, Taylor R, Thielke R, Payne J, Gonzalez N, Conde JG. Research electronic data capture (REDCap)--a metadata-driven methodology and workflow process for providing translational research informatics support. J Biomed Inform. Apr 2009;42(2):377-81. doi:10.1016/j.jbi.2008.08.010 
Table 1 | Baseline characteristics of patients

\begin{tabular}{|c|c|c|c|}
\hline & $\operatorname{SOC}(n=41)$ & Sargramostim $(n=40)$ & All patients $(n=81)$ \\
\hline $\begin{array}{l}\text { Age at randomization } \\
\qquad \begin{array}{l}\text { Median (IQR) }-\mathrm{yr} \\
\text { Age } \geq 65 \mathrm{yr}-\mathrm{n}(\%)\end{array}\end{array}$ & $\begin{array}{l}60(53-69) \\
15(36.6) \\
\end{array}$ & $\begin{array}{l}59(46-68) \\
11(27.5)\end{array}$ & $\begin{array}{l}60(49-69) \\
26(32.1)\end{array}$ \\
\hline Male sex $-\mathrm{n}(\%)$ & $25(61.0)$ & $26(65.0)$ & $51(63.0)$ \\
\hline $\begin{array}{l}\text { Ethnicity } \\
\qquad \begin{array}{l}\text { White }-\mathrm{n}(\%) \\
\text { Black }-\mathrm{n}(\%) \\
\text { Arabian }-\mathrm{n}(\%)\end{array}\end{array}$ & $\begin{array}{l}39(95.1) \\
0(0.0) \\
2(4.9)\end{array}$ & $\begin{array}{l}34(85.0) \\
4(10.0) \\
2(5.0)\end{array}$ & $\begin{array}{l}73(90.1) \\
4(4.9) \\
4(4.9)\end{array}$ \\
\hline BMI - Median (IQR) & $27.6(24.7-33.1)$ & $28.6(26.0-33.8)$ & $28.0(25.0-33.4)$ \\
\hline Days since symptom onset - Median (IQR) & $10.0(9.0-13.0)$ & $11.0(8.5-14.0)$ & $11.0(9.0-13.0)$ \\
\hline Days since hospitalization - Median (IQR) & $3.0(3.0-5.0)$ & $3.0(2.5-4.5)$ & $3.0(3.0-5.0)$ \\
\hline $\begin{array}{l}\text { Comorbidity }-\mathrm{n}(\%) \\
\text { Arterial hypertension } \\
\text { Diabetes mellitus } \\
\text { Cardiovascular disease } \\
\text { Chronic kidney disease } \\
\text { Severe liver disease } \\
\text { Chronic lung disease } \\
\text { Cancer }\end{array}$ & $\begin{array}{l}7(17.1) \\
7(17.1) \\
1(2.4) \\
1(2.4) \\
0(0.0) \\
0(0.0) \\
2(4.9)\end{array}$ & $\begin{array}{l}7(17.5) \\
9(22.5) \\
0(0.0) \\
0(0.0) \\
0(0.0) \\
0(0.0) \\
2(5.0)\end{array}$ & $\begin{array}{l}14(17.3) \\
16(19.8) \\
1(1.2) \\
1(1.2) \\
0(0.0) \\
0(0.0) \\
4(4.9)\end{array}$ \\
\hline $\begin{array}{c}\text { Smoking status }-\mathrm{n}(\%) \\
\text { Current } \\
\text { Former }\end{array}$ & $\begin{array}{l}3(7.3) \\
16(39.0)\end{array}$ & $\begin{array}{l}0(0.0) \\
18(45.0)\end{array}$ & $\begin{array}{l}3(3.7) \\
34(42.0)\end{array}$ \\
\hline $\begin{array}{l}\text { Concomitant medication at randomization }-\mathrm{n}(\%) \\
\text { Glucocorticoids } \\
\text { Antiviral drugs (remdesivir) } \\
\text { Hydroxychloroquine } \\
\text { Antibiotics }\end{array}$ & $\begin{array}{l}9(22.0) \\
0(0.0) \\
26(63.4) \\
2(4.9)\end{array}$ & $\begin{array}{l}11(27.5) \\
3(7.5) \\
24(60.0) \\
1(2.5)\end{array}$ & $\begin{array}{l}20(24.7) \\
3(3.7) \\
50(61.7) \\
3(3.7)\end{array}$ \\
\hline $\begin{array}{l}\text { Oxygenation }-\mathrm{Median}(\mathrm{IQR}) \\
\qquad \begin{array}{l}\mathrm{PaO}_{2} / \mathrm{FiO}_{2} \text { ratio }(\mathrm{mmHg}) \\
\mathrm{P}(\mathrm{A}-\mathrm{a}) \mathrm{O}_{2} \text { gradient }(\mathrm{mmHg})\end{array}\end{array}$ & $\begin{array}{l}297.00(242.00-319.50) \\
45.55(38.60-61.75)\end{array}$ & $\begin{array}{l}291.50(251.50-329.00) \\
50.15(39.80-63.75)\end{array}$ & $\begin{array}{l}295.00(248.00-328.00) \\
47.65(38.90-61.75)\end{array}$ \\
\hline $\begin{array}{l}\text { Lab values - Median (IQR) } \\
\qquad \begin{array}{l}\text { C-reactive protein level (mg/l) } \\
\left.\text { Eosinophil count ( } \times 10^{9} / \mathrm{I}\right) \\
\text { Lymphocyte count }\left(\times 10^{9} / \mathrm{I}\right) \\
\text { Ferritin }(\mu \mathrm{g} / \mathrm{I}) \\
\text { D-Dimer }(\mathrm{nmol} / \mathrm{I}) \\
\text { Lactate dehydrogenase (ukat/)I } \\
\text { Asparate aminotransferase (ukat/I) } \\
\text { Alanine aminotransferase (ukat/I) } \\
\text { Creatinine }(\mu \mathrm{mol} / \mathrm{I})\end{array}\end{array}$ & $\begin{array}{l}83.00(38.40-180.00) \\
0.02(0.00-0.09) \\
0.88(0.65-1.22) \\
721.00(425.00-1068.00) \\
3.61(2.39-5.04) \\
5.98(4.31-6.86) \\
0.65(0.57-0.89) \\
0.57(0.40-0.92) \\
78.68(68.07-92.82)\end{array}$ & $\begin{array}{l}73.20(39.10-122.80) \\
0.01(0.00-00.10) \\
1.08(0.83-1.40) \\
736.50(446.50-1063.50 \\
4.36(3.12-5.80) \\
4.98(4.14-6.40) \\
0.62(0.44-1.01) \\
0.59(0.38-0.86) \\
75.14(68.07-88.40)\end{array}$ & $\begin{array}{l}74.50(38.75-147.45) \\
0.02(0.00-0.10) \\
1.00(0.70-1.30) \\
721.00(425.00-1068.00) \\
3.81(2.79-5.31) \\
5.26(4.21-6.68) \\
0.65(0.48-0.95) \\
0.58(0.40-0.89) \\
77.35(68.07-92.82)\end{array}$ \\
\hline $\begin{array}{l}\text { Biomarkers in serum - Median (IQR) } \\
\text { IL1RA (ng/ml) } \\
\text { IL-6 }(\mathrm{pg} / \mathrm{ml}) \\
\mathrm{IL}-8(\mathrm{pg} / \mathrm{ml}) \\
\mathrm{IL}-18(\mathrm{pg} / \mathrm{ml}) \\
\mathrm{C} 5 \mathrm{a}(\mathrm{ng} / \mathrm{ml}) \\
\text { GM-CSF }(\mathrm{fg} / \mathrm{ml}) \\
\text { TNF }(\mathrm{pg} / \mathrm{ml})\end{array}$ & $\begin{array}{l}1288.00(905.10-2350.00) \\
11.54(4.85-36.84) \\
27.44(15.91-46.49) \\
150.70(87.13-198.30) \\
8.83(4.52-16.06) \\
9.12(6.82-13.39) \\
14.77(8.53-25.91)\end{array}$ & $\begin{array}{l}839.30(595.80-1494.00) \\
11.47(4.50-21.73) \\
22.51(14.14-32.11) \\
101.30(73.80-164.70) \\
11.18(3.91-16.28) \\
9.13(7.35-12.42) \\
16.32(12.17-20.13)\end{array}$ & $\begin{array}{l}1162,00(678.40-1806.00) \\
11,54(4,85-24,90) \\
23.99(15.91-39.73) \\
131.00(80.32-184.80) \\
9.94(4.37-16.12) \\
9.12(7.05-12.71) \\
14.99(10.66-22.28)\end{array}$ \\
\hline SOFA score - Median (IQR) & $2.0(1.0-3.0)$ & $2.0(1.0-2.0)$ & $2.0(1.0-2.0)$ \\
\hline $\begin{array}{l}\text { 6-category ordinal scale at randomization - no. (\%) } \\
\text { (\%)spitalized, on non-invasive ventilation or high } \\
\text { flow oxygen devices } \\
4 \text { Hospitalized, requiring supplemental oxygen } \\
5 \text { Hospitalized, not requiring supplement oxygen }\end{array}$ & $\begin{array}{l}5(12.2) \\
33(80.5) \\
3(7.3)\end{array}$ & $\begin{array}{l}1(2.5) \\
38(95.0) \\
1(2.5)\end{array}$ & $\begin{array}{l}6(7.4) \\
71(87.7) \\
4(4.9)\end{array}$ \\
\hline
\end{tabular}




\begin{tabular}{|c|c|c|c|}
\hline & $\begin{array}{c}\text { SOC } \\
(n=41)\end{array}$ & $\begin{array}{l}\text { Sargramostim } \\
\quad(n=40)\end{array}$ & P Value \\
\hline \multicolumn{4}{|l|}{ Primary endpoints } \\
\hline $\begin{array}{l}\text { Number of patients with } \geq \mathbf{2 5 \%} \\
\text { Reduction Change from Baseline in } \mathbf{P}(\mathbf{A}-\mathbf{a}) \\
\text { Gradient on Day } 6^{*}-\text { no./total no. (\%) }\end{array}$ & $15 / 38(39.5)$ & $22 / 35(62.9)$ & $0.0459^{c}$ \\
\hline $\begin{array}{l}\text { Number of patients with } \geq \mathbf{3 3 \%} \\
\text { Reduction Change from Baseline in } \mathbf{P}(\mathbf{A}-\mathbf{a}) \\
\text { Gradient on Day } 6^{*}-\text { no./total no. }(\%)\end{array}$ & $10 / 38(26.3)$ & $19 / 35(54.3)$ & $0.0147^{c}$ \\
\hline $\begin{array}{l}\text { Number of patients with } \geq \mathbf{5 0 \%} \\
\text { Reduction Change from Baseline in } \mathbf{P}(\mathbf{A}-\mathrm{a}) \\
\text { Gradient on Day } 6 *-\text { no./total no. }(\%)\end{array}$ & $6 / 38(15.8)$ & $12 / 35(34.3)$ & $0.1023^{F}$ \\
\hline $\begin{array}{l}\text { Median Change from Baseline in } \mathrm{P}(\mathrm{A}-\mathrm{a}) \\
\text { Gradient on Day } 6 *(95 \% \mathrm{Cl})\end{array}$ & $\begin{array}{l}-9.4 \\
(-13.4,6.2)\end{array}$ & $\begin{array}{l}-16.5 \\
(-23.6,-8.7)\end{array}$ & $0.1292^{\mathrm{M}}$ \\
\hline $\begin{array}{l}\text { Number of patients with } \geq \mathbf{2 5 \%} \text { Increase } \\
\text { Change from Baseline in PaO2/FiO2 on } \\
\text { Day } 6^{*}-\text { no./total no. (\%) }\end{array}$ & $11 / 38(28.9)$ & $11 / 35(31.4)$ & $0.8175^{C}$ \\
\hline $\begin{array}{l}\text { Number of patients with } \geq 33 \% \text { Increase } \\
\text { Change from Baseline in PaO2/FiO2 on } \\
\text { Day 6* - no./total no. (\%) }\end{array}$ & $6 / 38(15.8)$ & $6 / 35(17.1)$ & $>0.9999^{F}$ \\
\hline $\begin{array}{l}\text { Number of patients with } \geq 50 \% \text { Increase } \\
\text { Change from Baseline in } \mathrm{PaO2} / \mathrm{FiO2} \text { on } \\
\text { Day } 6^{*}-\text { no./total no. (\%) }\end{array}$ & $4 / 38(10.5)$ & $3 / 35(8.6)$ & $>0.9999^{F}$ \\
\hline $\begin{array}{l}\text { Median Change from Baseline in } \\
\mathrm{PaO} 2 / \mathrm{FiO} 2 \text { on Day } 6 *(95 \% \mathrm{Cl})\end{array}$ & $\begin{array}{l}+20.0 \\
(-10,61)\end{array}$ & $\begin{array}{l}+58.0 \\
(-3,64)\end{array}$ & $0.0818^{\mathrm{M}}$ \\
\hline \multicolumn{4}{|l|}{ Secondary endpoints } \\
\hline $\begin{array}{l}\text { Median change in 6-point ordinal scale } \\
\text { change between Baseline and Day } 6 \text { (95\% } \\
\text { Cl) }\end{array}$ & $0(0,1)$ & $0(0,1)$ & $0.5838^{\mathrm{M}}$ \\
\hline $\begin{array}{l}\text { Median number of days in hospital (95\% } \\
\mathrm{Cl})\end{array}$ & $9.0(7,14)$ & $8.5(6,12)$ & $0.9093^{\mathrm{M}}$ \\
\hline $\begin{array}{l}\text { Incidence of nosocomial infection - } \\
\text { no./total no. (\%) }\end{array}$ & $1 / 41(2.4)$ & $2 / 40(5.0)$ & $0.1655^{\mathrm{W}}$ \\
\hline Death at 28 days - no. (\%) & $2 / 41(4.9)$ & $2 / 40(5.0)$ & $>0.9999^{F}$ \\
\hline $\begin{array}{l}\text { Incidence of progression to mechanical } \\
\text { ventilation and/or ARDS - no./total no. } \\
\text { (\%) }\end{array}$ & $6 / 41(14.6)$ & $7 / 40(17.5)$ & $0.7254^{c}$ \\
\hline $\begin{array}{l}\text { Median Change Ferritin level between } \\
\text { Baseline and Day } 6(95 \% \mathrm{Cl})\end{array}$ & $\begin{array}{l}-112 \\
(-259,118)\end{array}$ & $\begin{array}{l}-90 \\
(-150,34)\end{array}$ & $0.8974^{\mathrm{M}}$ \\
\hline $\begin{array}{l}\text { Median Change D-dimer level between } \\
\text { Baseline and Day } 6(95 \% \mathrm{Cl})\end{array}$ & $\begin{array}{l}-0.44 \\
(-2.90,2.46)\end{array}$ & $\begin{array}{l}-0.71 \\
(-1.79,1.33)\end{array}$ & $0.7172^{\mathrm{M}}$ \\
\hline $\begin{array}{l}\text { Median Change CRP level between } \\
\text { Baseline and Day } 6(95 \% \mathrm{Cl})\end{array}$ & $\begin{array}{l}-43.1 \\
(-73.8,-22.8)\end{array}$ & $\begin{array}{l}-43.6 \\
(-69.8,-21.7)\end{array}$ & $0.8974^{\mathrm{M}}$ \\
\hline $\begin{array}{l}\text { Median Change Lymphocyte number } \\
\text { between Baseline and Day } 6(95 \% \mathrm{Cl})\end{array}$ & $\begin{array}{l}0.20 \\
(0.02,0.56)\end{array}$ & $\begin{array}{l}0.45 \\
(0.18,0.70)\end{array}$ & $0.2650^{\mathrm{M}}$ \\
\hline
\end{tabular}




\begin{tabular}{|l|l|l|l|}
\hline $\begin{array}{l}\text { Median Change Eosinophil number } \\
\text { between Baseline and Day 6 }(95 \% \mathrm{Cl})\end{array}$ & $\begin{array}{l}0.005 \\
(0.000,0.073)\end{array}$ & $\begin{array}{l}0.100 \\
(0.010,0.160)\end{array}$ & $0.1079^{\mathrm{M}}$ \\
\hline HRCT fibrosis score at follow-up (95\% Cl) & $\begin{array}{l}102.5 \\
(100.0,105.8)\end{array}$ & $\begin{array}{l}100.8 \\
(100.0,102.5)\end{array}$ & $0.5696^{\mathrm{M}}$ \\
\hline
\end{tabular}

* Day 6 or hospital discharge, whichever came first

${ }^{c}$ Chi-square Test

${ }^{\mathrm{F}}$ Fisher's Exact Test

${ }^{\mathrm{M}}$ Brown-Mood Test; ${ }^{\mathrm{w}}$ Wald test

HRCT fibrosis score is based on the collected average of the six individual HRCT zone scores. 
Table 3 | Safety and most common TEAE and serious TEAEs

\begin{tabular}{|c|c|c|c|}
\hline & $\begin{array}{c}\text { SOC } \\
(n=41)\end{array}$ & $\begin{array}{l}\text { Sargramostim } \\
\quad(n=40)\end{array}$ & $\begin{array}{c}\text { Total } \\
(n=81)\end{array}$ \\
\hline \multicolumn{4}{|l|}{ Adverse event } \\
\hline Patients with $\geq 1$ event - no. (\%) & $33(80.5)$ & $30(75.0)$ & $63(77.8)$ \\
\hline No. of events & 114 & 139 & 253 \\
\hline \multicolumn{4}{|l|}{ Serious adverse event } \\
\hline Patients with $\geq 1$ event - no. (\%) & $4(9.8)$ & $6(15.0)$ & $10(12.3)$ \\
\hline No. of events & 13 & 15 & 28 \\
\hline \multicolumn{4}{|l|}{ Adverse events not leading to mortality } \\
\hline Infectious disorder (not COVID-19) & $9(22.0)$ & $7(17.5)$ & $16(19.8)$ \\
\hline Epistaxis & $2(4.9)$ & $8(20.0)$ & $10(12.3)$ \\
\hline Constipation & $6(14.6)$ & $3(7.5)$ & $9(11.1)$ \\
\hline Thrombosis & $0(0.0)$ & $1(2.5)$ & $1(1.2)$ \\
\hline Acute kidney injury & $0(0.0)$ & $2(5.0)$ & $2(2.5)$ \\
\hline Cardiac disorder & $3(7.3)$ & $2(5.0)$ & $5(6.2)$ \\
\hline Abnormal liver-function & $0(0.0)$ & $1(2.5)$ & $1(1.2)$ \\
\hline Anaphylaxis & $0(0.0)$ & $0(0.0)$ & $0(0.0)$ \\
\hline \multicolumn{4}{|l|}{ Mortality - no. (\%) } \\
\hline COVID-19 & $1(2.4)$ & $0(0.0)$ & $1(1.2)$ \\
\hline Infectious disorder (not COVID-19) & $2(4.9)$ & $1(2.5)$ & $3(3.7)$ \\
\hline Nervous system disorder & $1(2.4)$ & $0(0.0)$ & $1(1.2)$ \\
\hline Other & $4(9.8)$ & $3(7.5)$ & $7(8.6)$ \\
\hline
\end{tabular}

* Between randomization and hospital discharge or death

Note: 'Epistaxis' and 'Constipation' are the preferred terms that have a > 10\% incidence in the overall population if grade I-II.

Note: No terms have $>5 \%$ incidence in the overall population if grade III-IV. 
Fig. 1

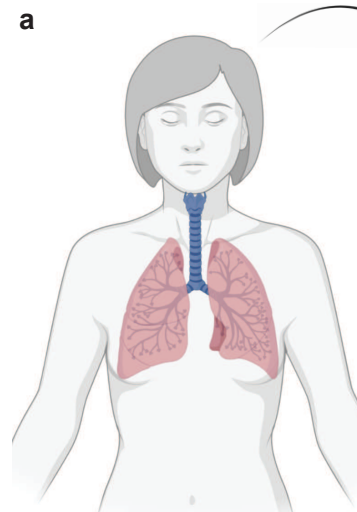

BAL cells Patients

c

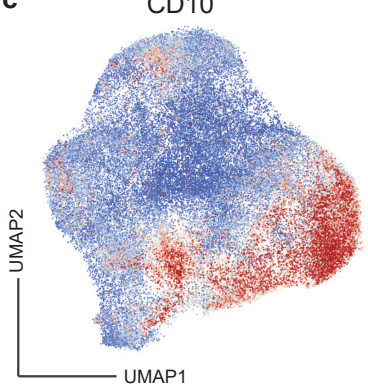

e Healthy controls

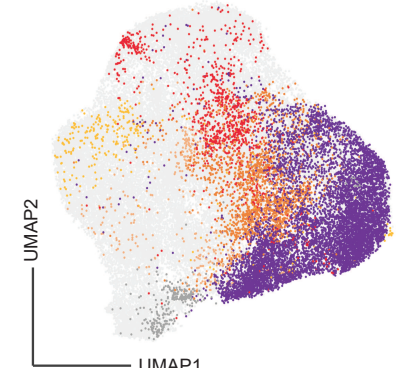

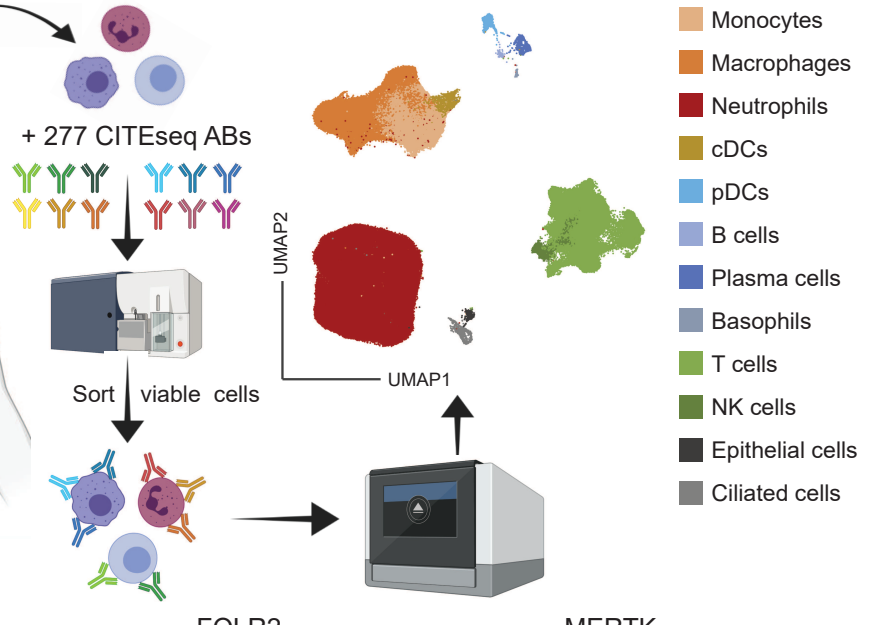

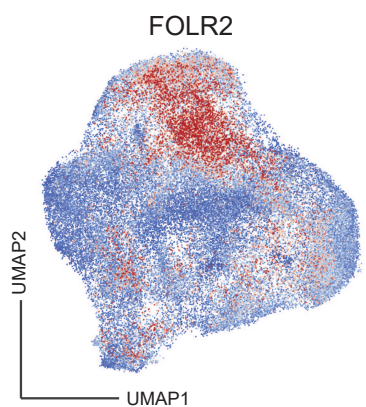

COVID-19 patients

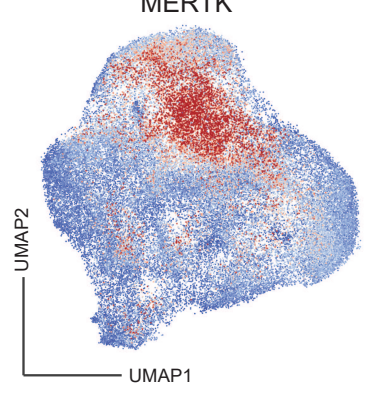

f Mono to mac trajectories

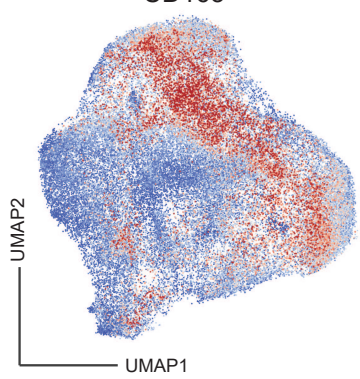

g

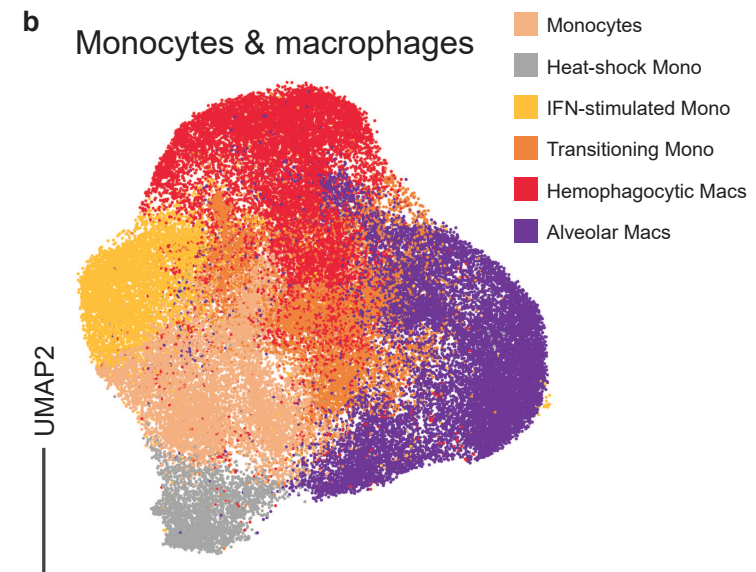

b Monocytes \& macrophages Monocytes

d
CD163

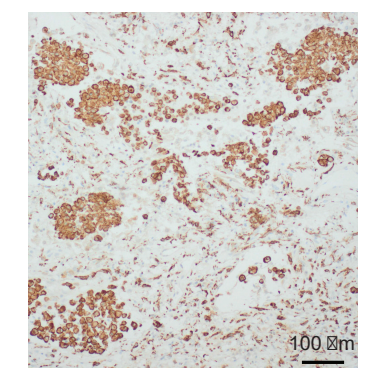

COVID-19 patients
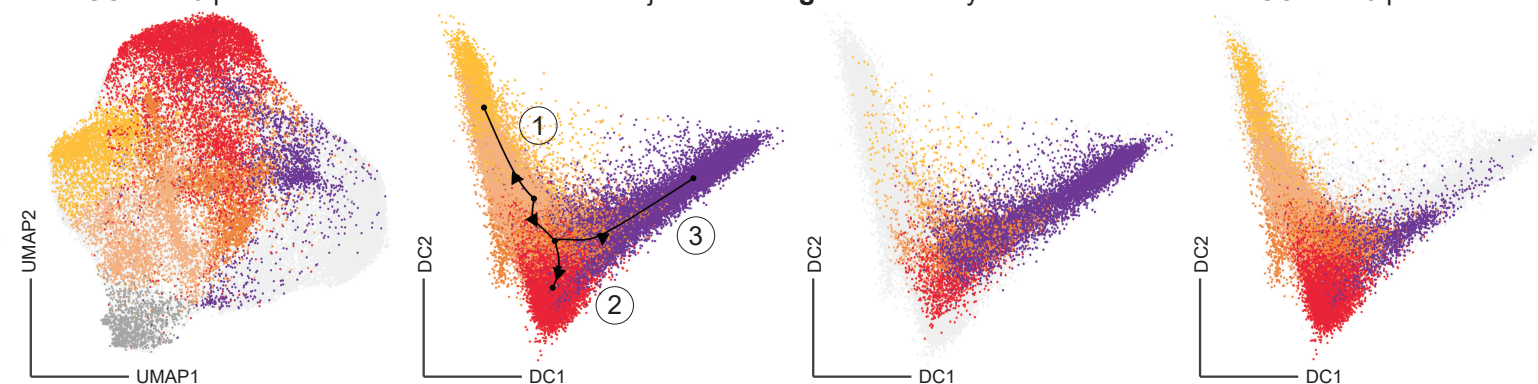

Mouse lung mac development

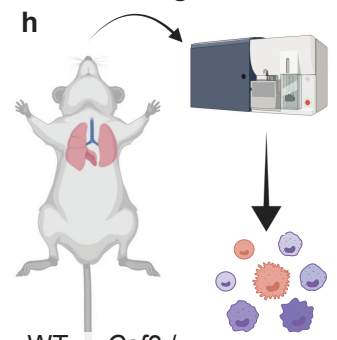

WT or Csf2-1PBS or rGM-CSF

Mini-bulk

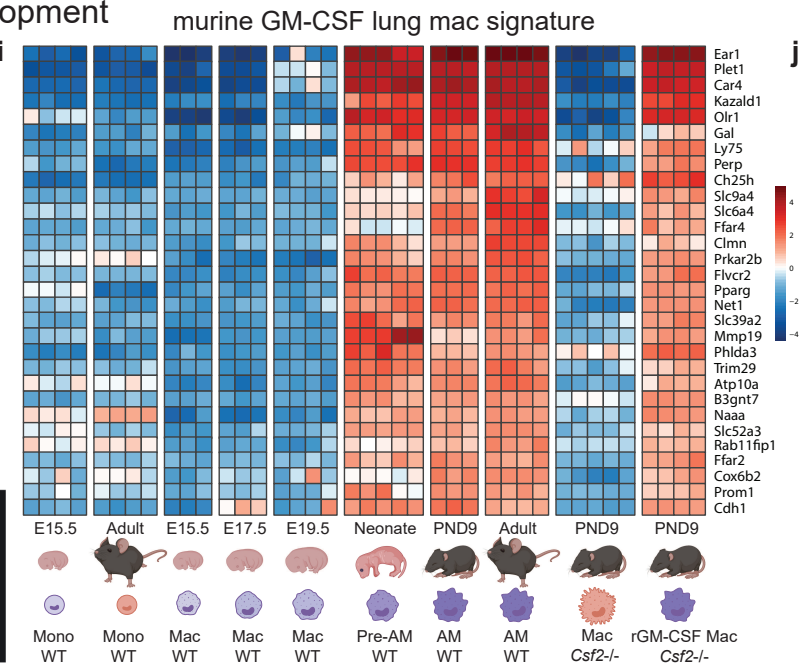

Projection of murine GM-CSF lung mac signatures on patient BAL data

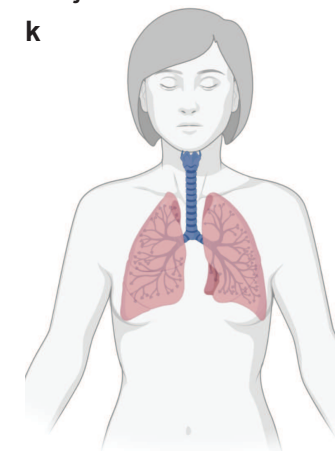

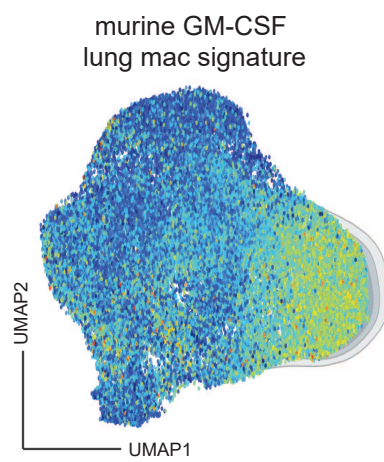

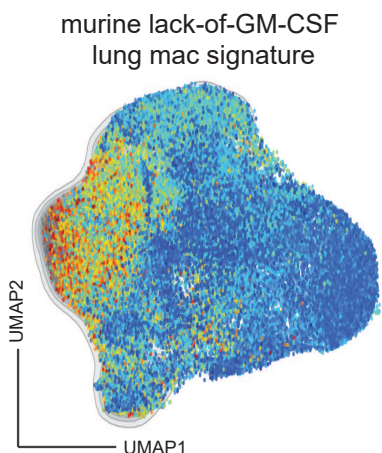

murine lack-of-GM-CSF lung mac signature

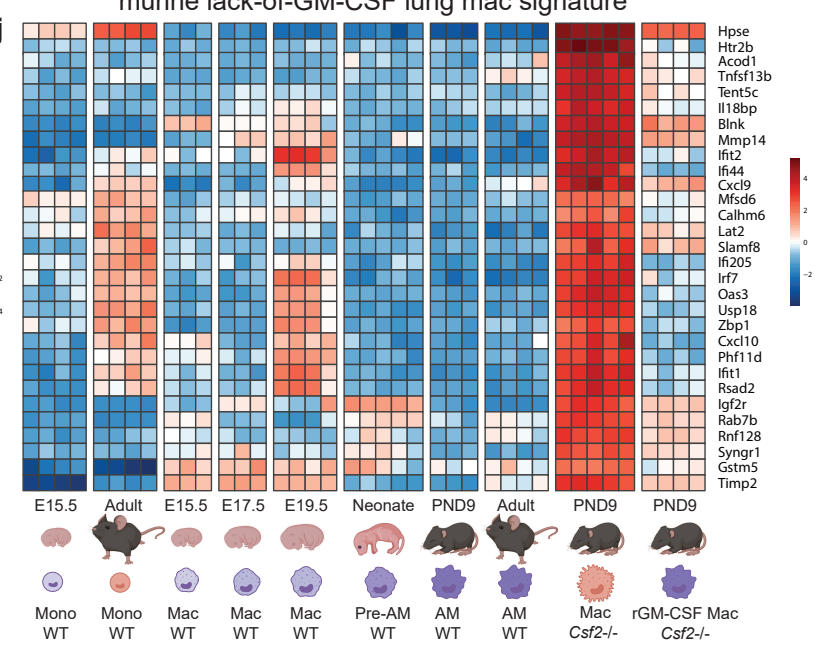

Conserved human-murine lung mac genes
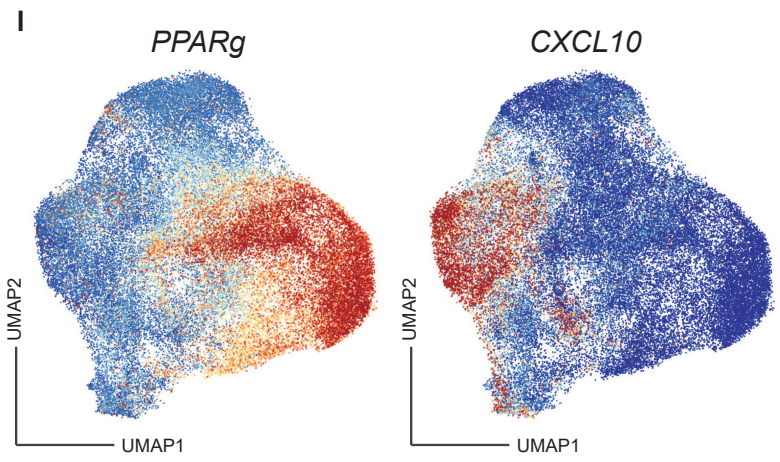
Fig. 2

Patients were screened for eligibility

6 Did not enrol

81 Underwent randomization

- 3 (7.5\%) No ABG

2 (5.0\%) Negative $P(A-a) O_{2}$ gradient

35 Reached primary endpoint

sargramostim and usual care

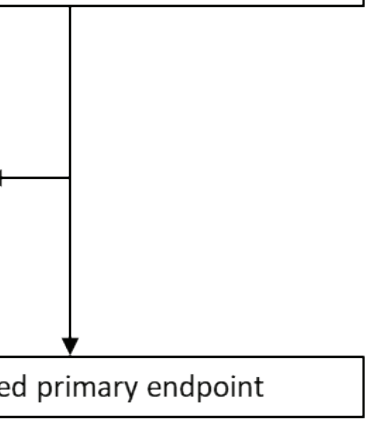

41 Were assigned to receive usual
care alone

41 Were assigned to receive usual
care alone

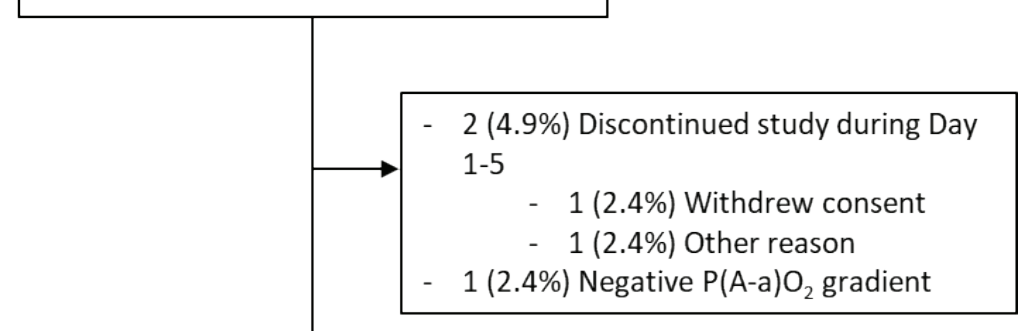

38 Reached primary endpoint 
Fig. 3

a

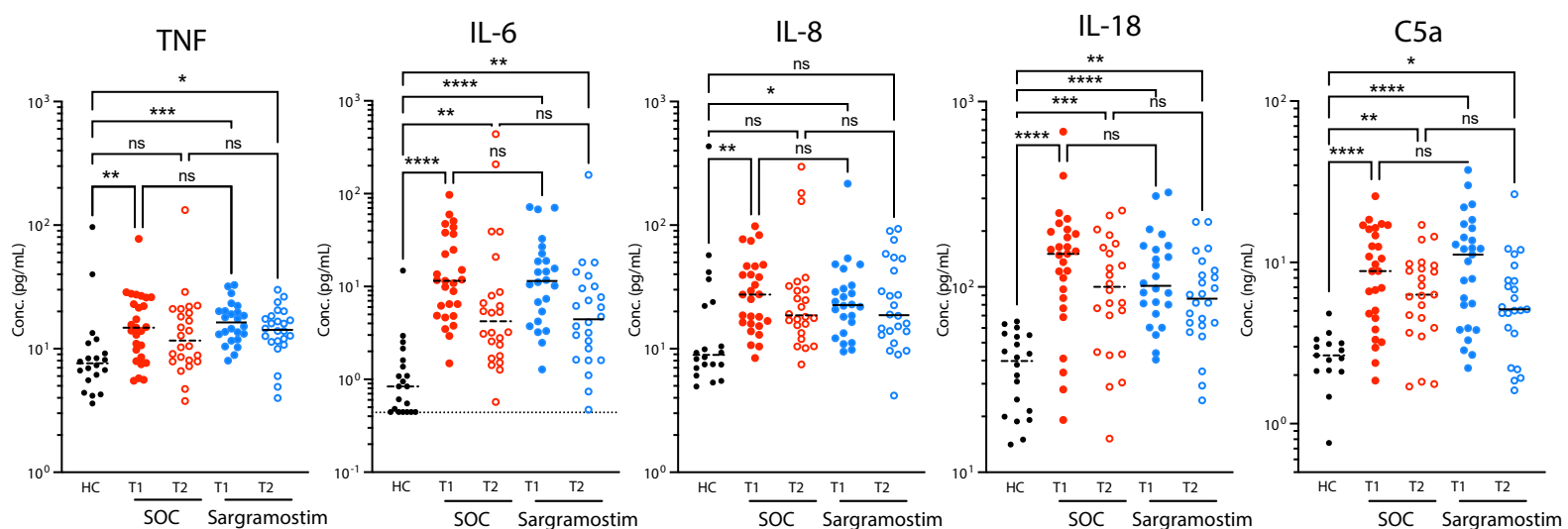

b

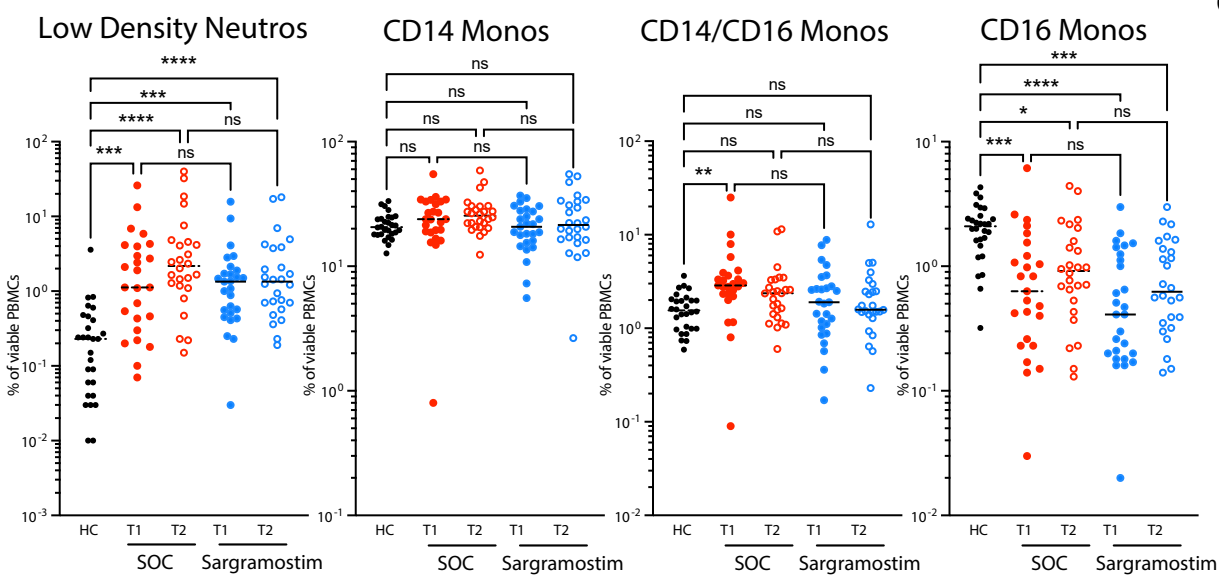

C

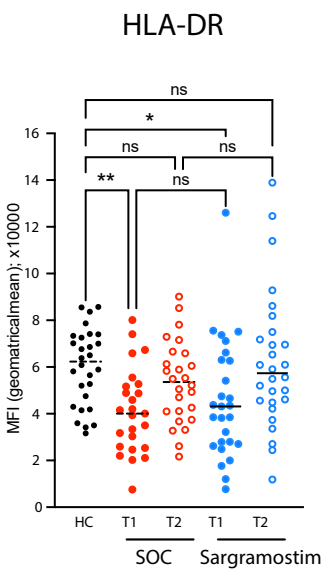

d

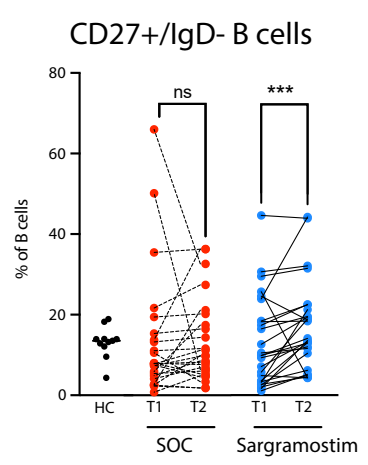

f

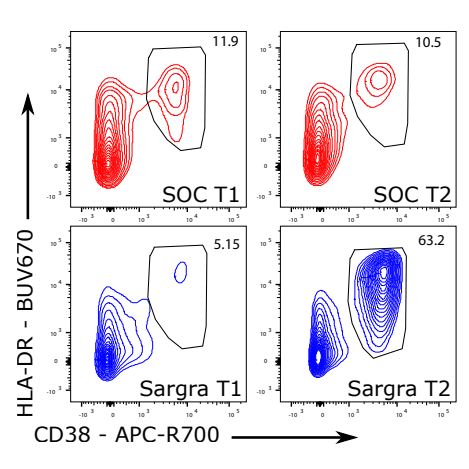

e

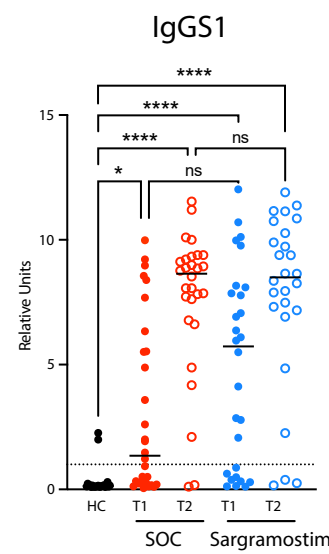

HLA-DR/CD38

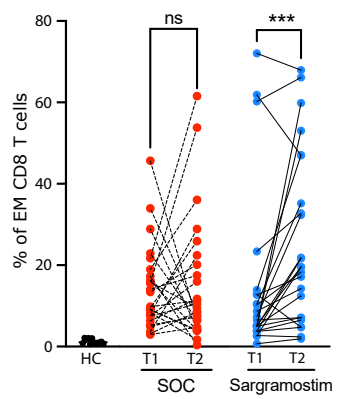

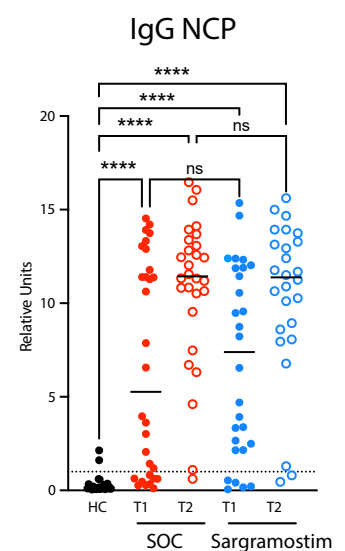

g

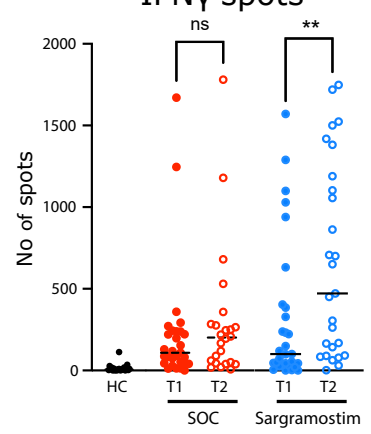

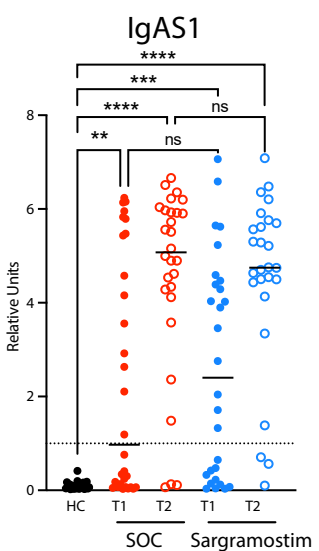

IFNy-IL2 spots

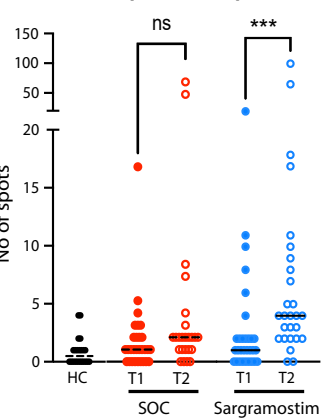




\section{Fig. 1 | Lack of alveolar macrophages and GM-CSF signature in COVID-19 patients}

a, Schematic overview of the single-cell-CITE-seq pipeline applied on cells isolated after BALF obtained from patients with COVID-19 $(n=8)$, non-COVID-19 pulmonary infection $(n=8)$, interstitial lung disease (ILD) $(n=1)$ and control non-infected individuals undergoing diagnostic bronchoscopy $(n=2)$. UMAP visualisation of the proteome- and transcriptome-based clustering of the BAL cells.

b, UMAP visualisation of the annotated BAL monocyte and macrophage clusters.

c, UMAP representing relative expression of key surface protein annotation markers (CD10, FOLR2, MERTK and CD163) through CITE-Seq on monocyte and macrophage subgroups (blue, low expression; red, high expression).

d, Immunohistochemistry analysis of CD163 expression on lung section of a patient succumbed to severe COVID-19.

e, UMAP visualisation of the annotated BAL monocyte and macrophage clusters in healthy control group (left) versus PCR-positive COVID-19 patient group (right).

f, Diffusion map and slingshot mediated trajectory inference starting from monocytes bifurcating to either IFN-stimulated monocytes (1), or via a transitional monocyte state to either hemophagocytic macrophages (2) or alveolar macrophages (3). DC, diffusion component.

g, Visualisation of the annotated BAL monocytes and macrophages from the healthy control group (left) versus COVID-19 patient group (right) on the diffusion map.

h, Schematic overview of mini-bulk micro-array setup used on monocytes and macrophages isolated from lungs of WT or Csf2\% mice after PBS or rGM-CSF treatment.

i, Heatmap showing the relative expression of the top genes present in the murine GM-CSF-dependent lung macrophage signature. The relative expression of these genes by monocytes or macrophages sorted from the lung at different time points during embryonic development or post-natally are shown. The relative expression of these genes by macrophages sorted from lungs of PND9 Csf2 $2^{-/}$mice treated with PBS (left) or rGM-CSF (right) is shown in the last two columns.

j, Heatmap showing the relative expression of the top genes present in the murine lack-of-GM-CSF lung macrophage signature. The relative expression of these genes by monocytes or macrophages sorted from the lung at different time points during embryonic development or post-natally are shown. The relative expression of these genes by macrophages sorted from lungs of PND9 Csf2-/- mice treated with rGM-CSF is shown in the last column.

$\mathbf{k}$, Projection of the murine GM-CSF lung macrophage signature on patient BAL CITE-Seq data. In the left UMAP, cells are highlighted that have a gene signature that corresponds to the murine GM-CSFdependent lung macrophage signature. In the right UMAP, cells are highlighted that have a gene signature that corresponds to the murine lack-of-GM-CSF lung macrophage signature.

I, UMAP representing the expression two conserved genes between human and mouse that represent a GM-CSF gene signature (PPARg, left UMAP) or a lack-of-GM-CSF gene signature (CXCL10, right UMAP). 
$B A L$, broncho-alveolar lavage; $C D C$, conventional dendritic cells; $P D C$, plasmacytoid dendritic cells; NK cells, natural killer cells, UMAP, uniform manifold approximation and projection; DC, diffusion component, rGM-CSF, recombinant granulocyte-macrophage colony-stimulating factor; PBS, Phosphate-buffered saline; WT, wild-type; CITE-Seq, Cellular Indexing of Transcriptomes and Epitopes by Sequencing; PND9, post-natal day 9. 
Fig. 2 | Study flow chart 


\section{Fig. 3 | Effect of sargramostim on immune landscape}

a, TNF, IL-6, IL-18 and C5a measured in serum of healthy control (HC), standard of care (SOC) and sargramostim group at baseline (T1) and after (T2) 5 days of treatment. HC (N = 20), SOC (N(T1) = 27; $\mathrm{N}(\mathrm{T} 2)=24)$ and sargramostim $(\mathrm{N}(\mathrm{T} 1)=24 ; \mathrm{N}(\mathrm{T} 2)=24)$ for TNF, IL-6, IL-8 and IL18. HC (N=15), SOC $(\mathrm{N}(\mathrm{T} 1)=27 ; \mathrm{N}(\mathrm{T} 2)=23)$ and sargramostim $(\mathrm{N}(\mathrm{T} 1)=27 ; \mathrm{N}(\mathrm{T} 2)=23)$ for C5a assay.

b, Percentage of low density neutrophils, $\mathrm{CD} 14^{+} \mathrm{CD} 16^{-}$monocytes, $\mathrm{CD} 14^{+} \mathrm{CD} 16^{+}$monocytes and $\mathrm{CD} 14^{-}$ CD16 ${ }^{+}$monocytes in PBMC fraction of healthy control ( $\left.\mathrm{HC} ; \mathrm{N}=28\right)$, standard of care $(\mathrm{SOC} ; \mathrm{N}(\mathrm{T} 1)=25$; $\mathrm{N}(\mathrm{T} 2)=26)$ and sargramostim group $(\mathrm{N}(\mathrm{T} 1)=27 ; \mathrm{N}(\mathrm{T} 2)=26)$ at baseline $(\mathrm{T} 1)$ and after (T2) 5 days of treatment.

c, Surface expression of HLA-DR (MFI) on inflammatory monocytes in PBMC fraction of healthy control ( $\mathrm{HC} ; \mathrm{N}=28)$, standard of care (SOC; $\mathrm{N}(\mathrm{T} 1)=25 ; \mathrm{N}(\mathrm{T} 2)=26$ ) and sargramostim group ( $\mathrm{N}(\mathrm{T} 1)=27 ; \mathrm{N}(\mathrm{T} 2)$ $=26)$ at baseline (T1) and after (T2) 5 days of treatment.

d, Percentage of switched memory B cells in PBMC fraction of in PBMC fraction of healthy control (HC; $N=11)$, standard of care (SOC; $N(T 1)=25 ; N(T 2)=25)$ and sargramostim group $(N(T 1)=26 ; N(T 2)=$ 26) at baseline (T1) and after (T2) 5 days of treatment.

e, IgG and IgA antibodies against SARS-CoV-2 Spike protein 1 (S1), and nucleocapsid protein (NCP)specific IgG antibodies detected by ELISA in healthy control (HC; $N=23$ ), standard of care (SOC; $N(T 1)$ $=30 ; \mathrm{N}(\mathrm{T} 2)=27)$ and sargramostim group $(\mathrm{N}(\mathrm{T} 1)=28 ; \mathrm{N}(\mathrm{T} 2)=26)$ at baseline $(\mathrm{T} 1)$ and after $(\mathrm{T} 2) 5$ days of treatment.

f, Flowcytometry plots pre-gated on live CD8 $\mathrm{T}$ cells and gated on HLA-DR ${ }^{+} \mathrm{CD} 38^{+}$fraction in representative PBMC sample for standard of care $(\mathrm{SOC})$ and sargramostim group (Sargra) at baseline (T1) and after (T2) 5 days of treatment. Percentage of activated (HLA-DR ${ }^{+}$CD38 $8^{+}$) CD8 T cells in PBMC fraction of healthy control ( $\mathrm{HC} ; \mathrm{N}=11$ ), standard of care $(\mathrm{SOC} ; \mathrm{N}(\mathrm{T} 1)=25 ; \mathrm{N}(\mathrm{T} 2)=25)$ and sargramostim group $(\mathrm{N}(\mathrm{T} 1)=26 ; \mathrm{N}(\mathrm{T} 2)=26)$ at baseline $(\mathrm{T} 1)$ and after $(\mathrm{T} 2) 5$ days of treatment.

g, Absolute number of $\mathrm{FNg}^{+}$(left) or IFNg ${ }^{+} \mathrm{IL}_{-2}{ }^{+}$(right) spots detected by ELISpot after CD8 T cell stimulation with SARS-CoV-2 peptide pools in healthy control (HC; $N=22$ ), standard of care (SOC; $N(T 1)$ $=29 ; \mathrm{N}(\mathrm{T} 2)=24)$ and sargramostim group $(\mathrm{N}(\mathrm{T} 1)=30 ; \mathrm{N}(\mathrm{T} 2)=27)$ at baseline $(\mathrm{T} 1)$ and after (T2) 5 days of treatment.

The comparisons were performed by the Kruskal Wallis test with Dunn's correction for panel a, b, c and e; and the Wilcoxon test for panel $d, f$, and $g$. The line in panel a, b, c, e and g indicates the median. 


\section{Supplementary Files}

This is a list of supplementary files associated with this preprint. Click to download.

- Extendeddatatablesandfigures.pdf 